\title{
Paradigm Shift in the treatment of Class-II malocclusions in children and adolescents
}

\author{
P. Amat \\ Qualified Specialist in Dento-Facial Orthopedics, Private Practice at Le Mans. \\ Former assistant at Paris V University. \\ "The world hates change, yet it is the only thing that allowed it to progress." \\ Charles F. Kettering
}

SUMMARY:

In 1975, M. Chateau' ${ }^{16}$, wrote that only a first stage of treatment, by rigid bimaxillary hyperpropulsion, could correct mandibular retrognathism.

Since then, we have witnessed a double paradigm shift.

The first has seen the replacement of traditional sources of information, and their limitations, by access to the best published data, using an evidence-based approach. It has shed light on the debate about the treatment of Class-II malocclusions in children and adolescents, particularly on one-phase or two-phase treatments. Can a two-phase treatment increase the amount of mandibular growth in the long term? Can it increase the volume of the airways? Can it help prevent maxillary incisor trauma or root resorptions?

The second paradigm shift concerns the treatment of Class-II malocclusions in children and adolescents. To discover that the long-term skeletal effects of an initial phase of treatment are weak and clinically insignificant at best has been a bitter disappointment for our profession. But this new data also led to developments in treatment. The treatment of mandibular retrognathism has given way to an effective correction of Class-II malocclusions, which best suits the particular case of the patient, child, or adolescent.

\section{KEYWORDS}

Balance, therapeutic decision, mandibular retrognathism, treatment of Class-II malocclusions, evidence-based orthodontics

\section{INTRODUCTION}

The treatment of Class-II malocclusions is probably the most widely published subject of our clinical activity. For over a century, clinicians have been opposed to whether it is possible to treat mandibular retrognathism, by increasing the mandibular size in the long term.

The list of therapeutic proposals, which is already substantial, continues to grow with technical advances, the results of scientific publications, the emergence of new treatment philosophies, the opinions of eminent personalities, or the initiative of suppliers.

In 1975, among the indications for the use of removable devices for the treatment of Class-II malocclusions, M. Château and Y. Le Gall16, wrote that the indisputable first choice according to them when their article

\section{Address for correspondence:}

Philippe Amat-19, place des Comtes du 
was published, was mandibular retrognathism.

Mr. Chateau ${ }^{15}$, who found a confirmation of his ideas in the work of Pétro$\mathrm{vic}^{53,55}$, stated that "only bimaxillary, removable, and non-elastic hyperpulsive devices are convenient and effective for causing hyperactivity of propulsive muscles and activating mandibular growth in an anterior direction.

The treatment of a Class-II malocclusion with mandibular retrognathism therefore requires rigid bimaxillary hyperpropulsion as the first phase of treatment.

What is the situation today? Authors' opinions and published data, for example from the article by M. Château and Y. Le Gall ${ }^{16}$, are often contradictory. The relative lack of publications in the past and present can probably be explained to a large extent by the fact that the proposed therapeutic options work sufficiently well and often enough to allow for their subsequent use. So far, none of treatment options have been decisively demonstrated to be effective, which leads to doubts about the clear superiority of one of them.

Therefore, on what elements can clinicians rely on, to propose a treatment plan to his patient, which is not only effective but also the most appropriate for their individual case?

\section{The paradigm shift in clinical decision making}

Clinical decision making is by nature the core of the line of work of orthodontists and its most medical aspect ${ }^{5}$. The medical history, the clinical examination, and the supplementary examinations are the sources of information needed to reach a diagnosis. Where can we find other information needed for clinical decision making?

In the 1970s, only traditional sources of information were available, all of which had their own limitations:

- The contents of the clinical manuals could be quickly rendered obsolete;

- Authors' opinions may not have been validated scientifically;

- Clinical cases seen or read, could not account for the diversity of clinical solutions published in specialized journals;

- The scientific press was less easily accessible, because of a lack of electronic resources (access to e-databases and online journals);

- The methodological quality of the studies was inferior, and there were no systematic reviews of the literature.

Since the publication of the article by $M$. Château et Y. Le Gall ${ }^{16}$, a paradigm shift has occurred, thanks to the access to the best published data, using the evidence-based approach $^{4,61}$.

The use of evidence-based orthodontics (EBO) (Fig. 1) is easy, particularly in the user mode ${ }^{3}$, with the search for the best pre-evaluated data by means of the "6S" pyramid"23,29 (Fig. 2).

Among the incessant flow of scientific publications, the EBO helps us to quickly search and evaluate the methodological quality, select the best available information, combine them with our individual clinical competence, and thus deliver more effective care while taking into account the needs and the situation of our patients.

It has become essential and has helped to illuminate the debate around 


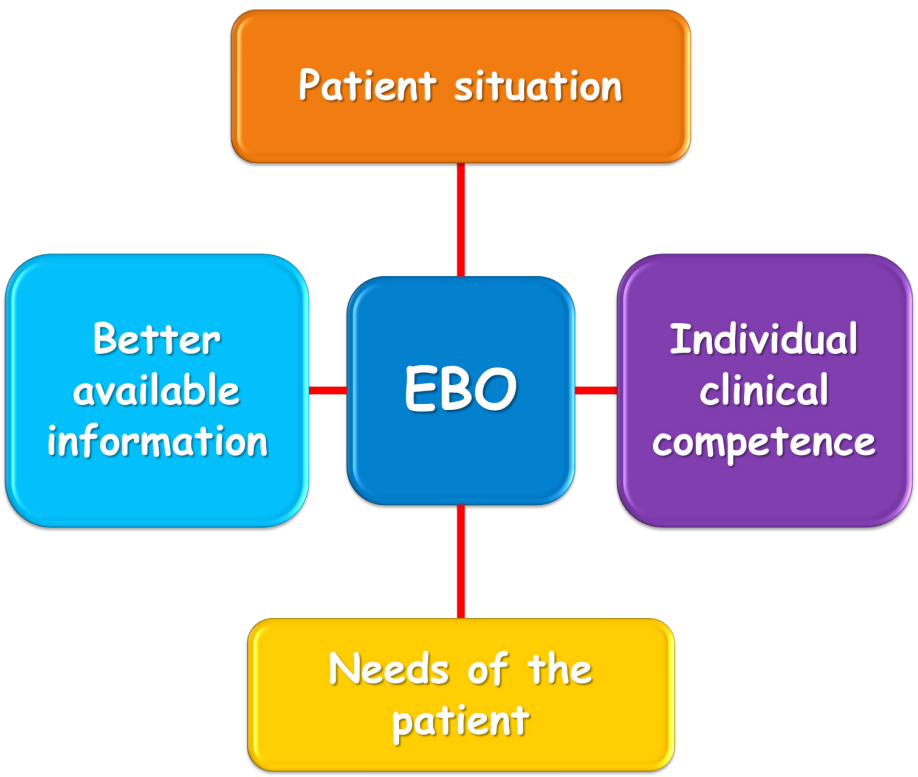

Figure 1

Clinical decision making with evidence-based orthodontics $(E B O)^{4}$.

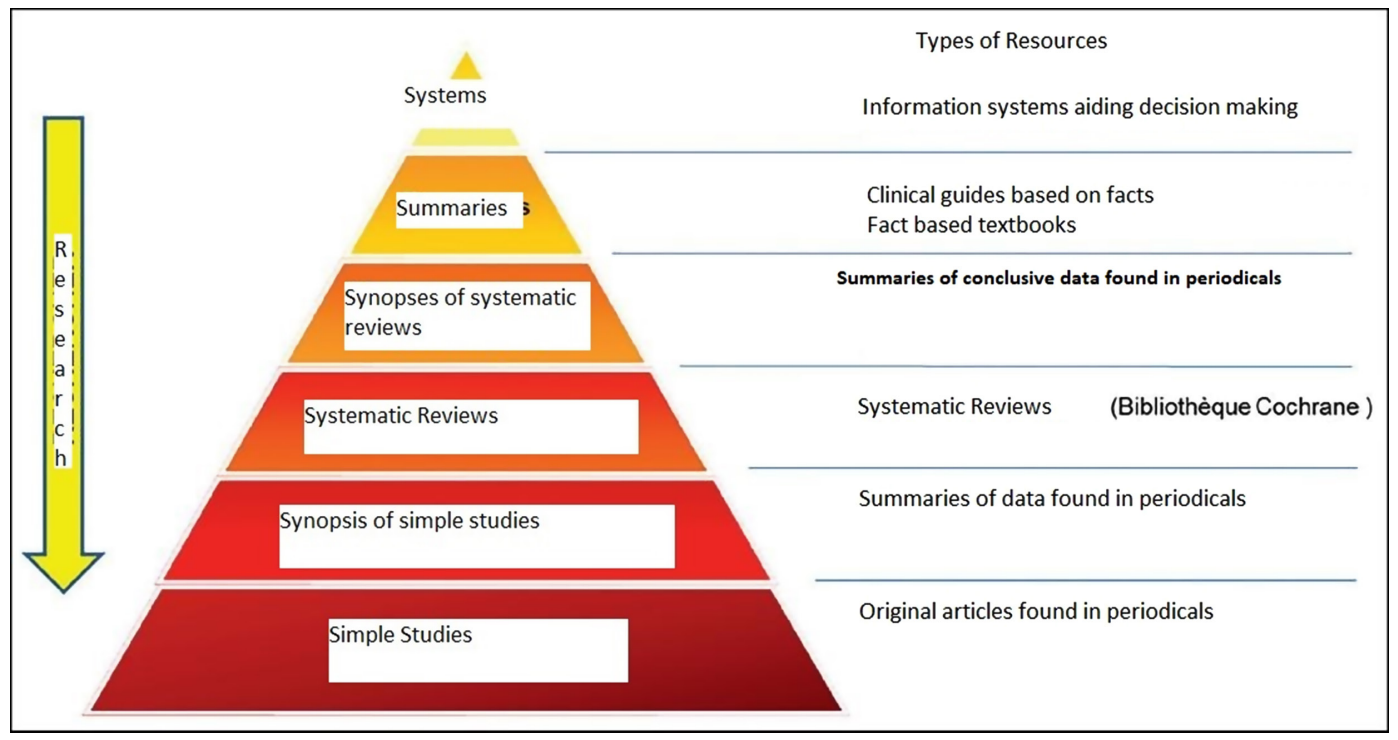

Figure 2

The 6S pyramid of pre-evaluated data. (adapted from DiCenso, Bayley, and Haynes ${ }^{23}$ ). 
the treatment of Class-II malocclusions in children and adolescents, particularly with one-phase or two-phase treatments.

Explaining how to assess the validity of the various current aspects of clinical decision making for the treatment of Class-II malocclusions in children and adolescents is inconsistent with the limited scope of an article. We will limit our talk to four questions for which the EBO helps to provide answers when making an informed choice of a therapeutic option for our patients.

\section{Can two-phase treatment increase the amount of mandibular growth in the long run?}

Since 1879, and the birth of functional treatments with Kingsley, which introduced the expression "Jumping the bite" and recommended treating mandibular retrognathism with forced mandibular propulsion, countless types of functional devices, and therapeutic modalities have been proposed. Although many publications ${ }^{18,43,69}$ have reported mandibular extension higher than those of untreated subjects after a functional treatment phase without the respective contributions, the treatment has been applied and favorable growth has been clearly established.

On the other hand, long-term studies on the treatment of Class-II malocclusions showed that if mandibular growth could be greater than that of untreated subjects during the functional treatment phase, it then declined. Only the rate of growth, not its quantity, seems to be modified ${ }^{22,46}$ (Fig. $3 a$ and b, Fig. 4a-d, Fig. 5a and b, Fig. 6a-c, Fig. 7a-c, Fig. 8a-c, Fig. 9a and b).
The recent Cochrane systematic review "Orthodontic treatment of prominent anterior maxillary teeth in children" 66 rules out long-term effects on mandibular growth.

The results of the last two systematic reviews ${ }^{20,52}$, published on this topic, indicate that the long-term skeletal effects of a first phase of treatment are weak and clinically insignificant at best.

\section{Can a two-phase treatment increase the volume of the airways?}

The prevalence of sleep ventilatory disorders was estimated to be $6 \%$ among adolescents, and these disorders are associated with increase in excessive daytime sleepiness, difficulties in learning in school, and the onset of attention deficit hyperactivity disorder (ADHD) 33 .

Mandibular retrognathism was identified as one of the predisposing factors of SVD ${ }^{37}$. It is associated with a constriction of the oropharyngeal pathways, which could be explained by a more pronounced position of the tongue base and the hyoid bone..$^{25,48}$

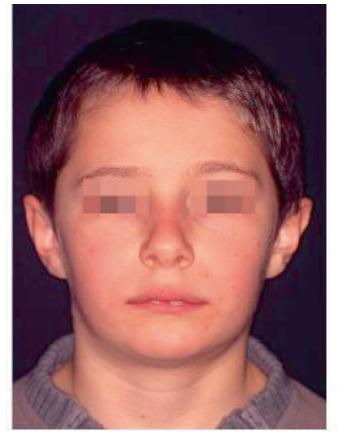

a

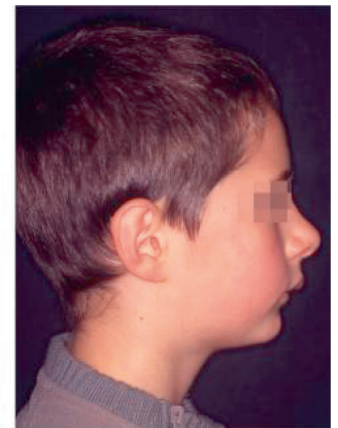

b
Figure 3

Case No. 1. Frontal (a) and profile

(b) portraits before treatment. 


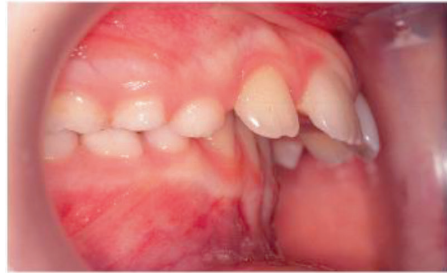

a

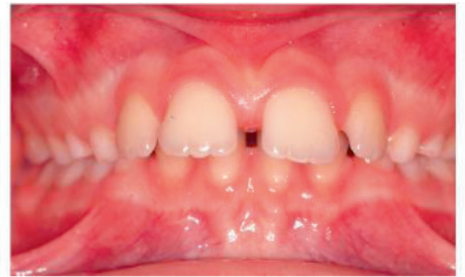

b

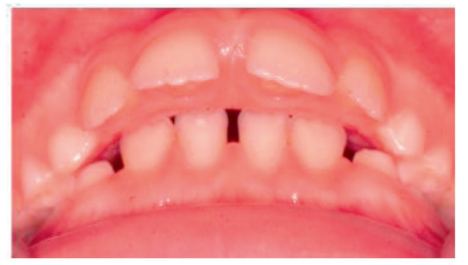

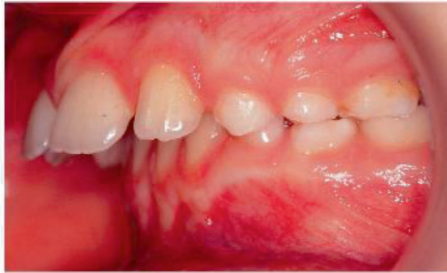

C

Figure 4

Intraoral views; right vestibular (a), frontal (b), left (c), and low-angle (d) views before treatment. The patient, aged 8 years 2 months, has a Class-II, Division 1, with full molar and canine Class-Il and a 13-mm overhang.

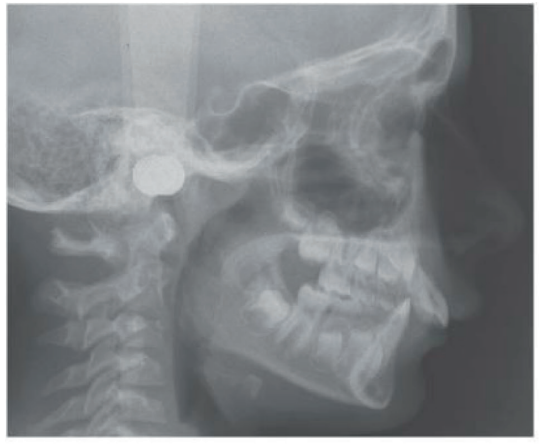

a

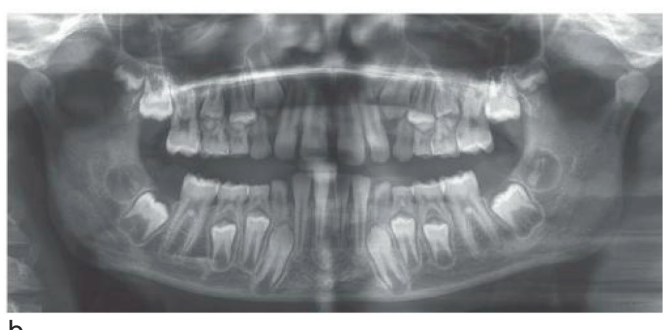

b

Figure 5

Profile (a) and panoramic (b) teleradiography before treatment. The patient presents a skeletal Class-Il with maxillary prognathism, mandibular retrognathism and anterior vertical deficiency.

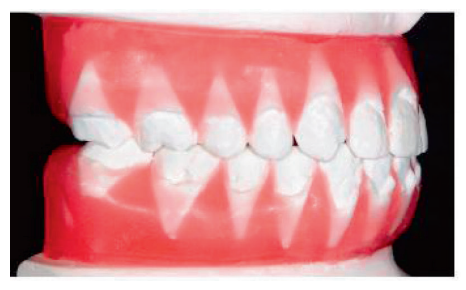

a

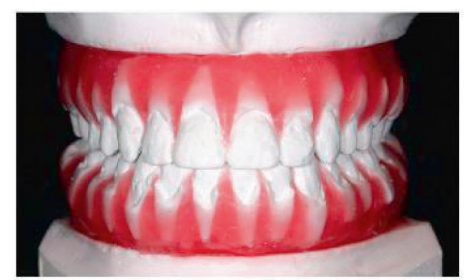

b

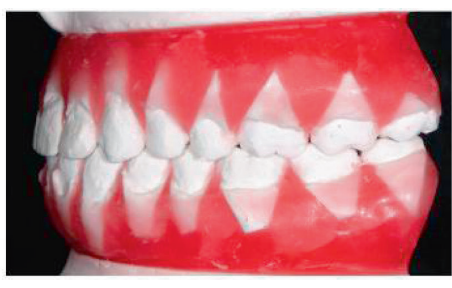

C

Figure 6

Right (a), front (b), and left (c) vestibular views of the fully individualized therapeutic setup on the SAM II articulator, which was used to manufacture the elasticated attachments (Laboratoire France Élastodontie ${ }^{\circledR}$ ). 


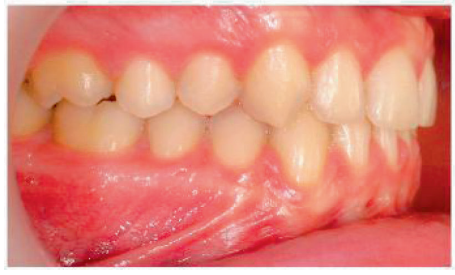

a

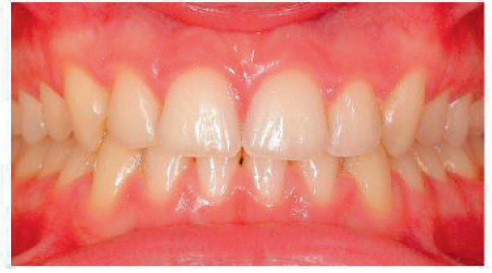

b

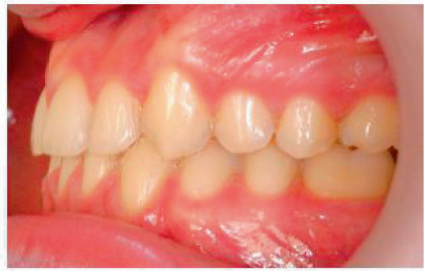

Figure 7

Vestibular Right (a), front (b), and left (c) intraoral views, showing the correction obtained at the end of the two-phase treatment, initially with a quad-helix and Class-II corrector ${ }^{6}$, then orthodontically with multibracket bimaxillary elasticated device. The port of the elasticated attachment will allow the gradual correction of the excess coronolingual torque of the maxillary canines.

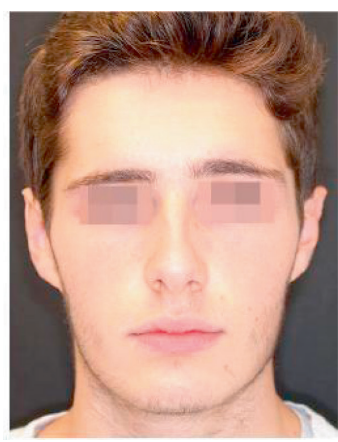

a

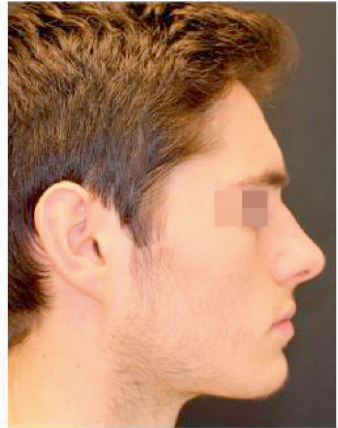

b

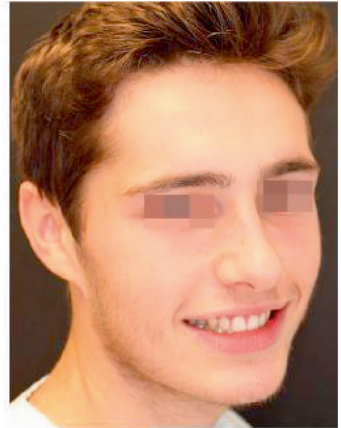

C

Figure 8

Face (a), profile (b), and three-quarter (c) portraits at the end of the two-phase treatment.

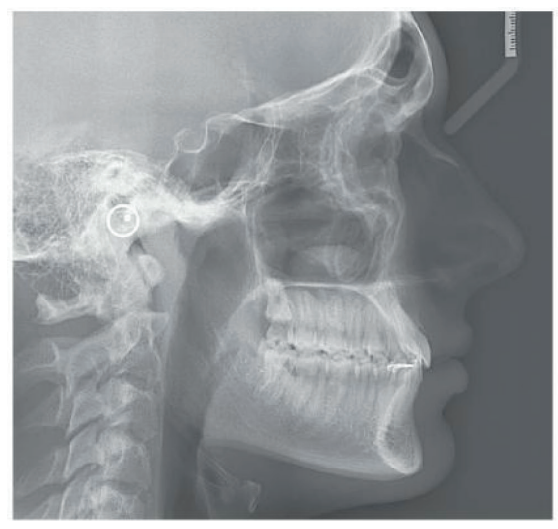

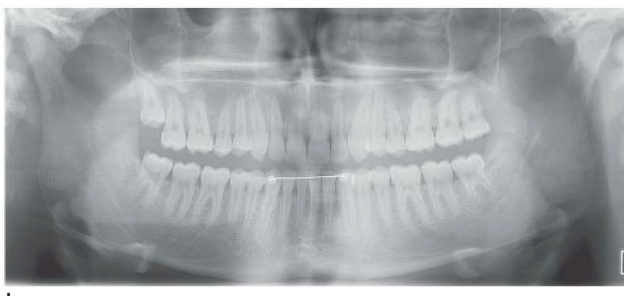

b

Figure 9

Profile (a) and panoramic (b) teleradiography, at the end of the two-phase treatment. 
Clinical studies show that functional device therapy increases the volume of the oropharyngeal pathways and the anteroposterior position of the hyoid bone, and helps patients with Class-II malocclusions $32,58,68,70$. (Fig. 10a and b, Fig. 11, Fig. 12).

If these results seem to be interesting, can it be said that they could contribute to the treatment of patients
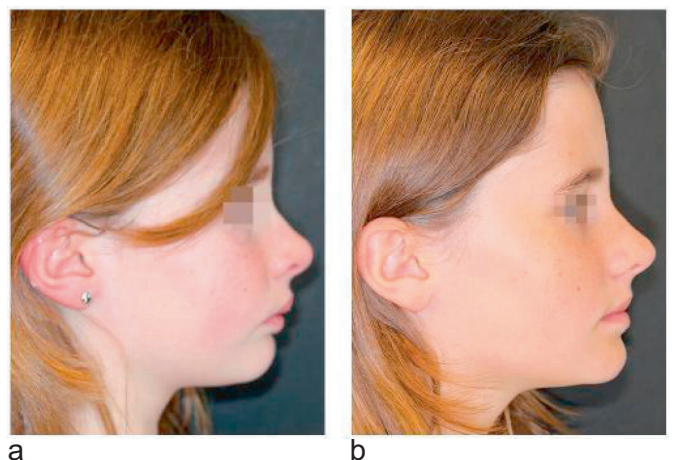

Figure 10

Case no. 2. Profile Portraits (a) before treatment and (b) after the first phase of the two-phase treatment.

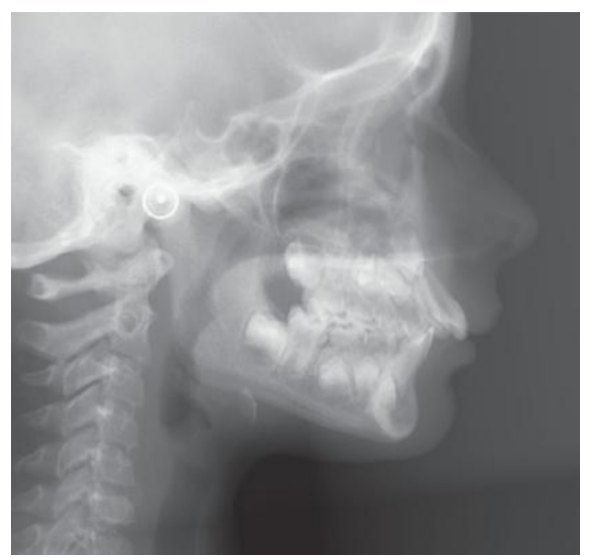

Figure 11

Profile teleradiography before treatment. A patient aged 8 years 3 months has a skeletal Class-I/ with maxillary prognathism and mandibular retrognathism.

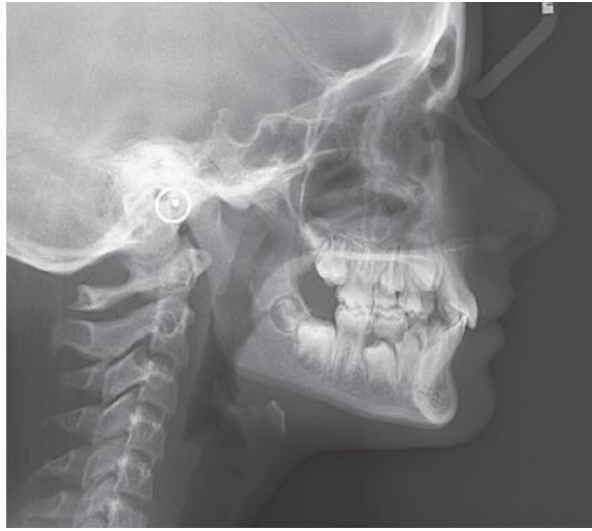

Figure 12

Profile teleradiography after the first treatment phase, by quad-helix and a Class-II corrector 6 . Note the anterior increase in the retrobasilingual space, partially related to the cephalic recovery observed on this teleradiography.

suffering from obstructive sleep apnea (OSA) syndrome? A recent systematic review is weakly affirmative ${ }^{30}$.

The last Cochrane systematic review $^{14}$, which represents the highest level of evidence currently available on this issue, was unable to conclude on the effectiveness or inefficiency of the use of functional devices for the treatment of OSA in children.

\section{Does a two-phase treatment help to prevent trauma to the axillary incisors?}

In children and adolescents, dental trauma represents an important public health problem, with a prevalence of $15 \%-30 \%$, and, if untreated, they are responsible for a deterioration of the patient's quality of life ${ }^{28}$.

Several studies have shown the existence of a positive correlation between 
the frequency of incisor trauma, the increase of incisor overhang, and labial incompetence ${ }^{13,49}$.

Their conclusions have since been strengthened by the publication of a systematic review and meta-analysis, devoted to the association between dental trauma and increased incisor overhang ${ }^{56}$. Its results show a double risk of trauma to the maxillary incisors, whose overhang is greater than 3-4 mm, among subjects.

It may therefore seem relevant to want to prevent the trauma of the maxillary incisors by a first phase of early treatment, which is confirmed by the Cochrane systematic review "Orthodontic treatment of prominent anterior maxillary teeth in children"66.

The authors conclude a significant decrease in the prevalence of incisor trauma, when the correction of an increased incisor overhang is obtained by a first phase of treatment in the child, compared to a treatment conducted in a single phase in early adolescence.

In particular, when the first phase of treatment was using functional devices (Fig. 13a-c, Fig. 14a-d, Fig. 15, Fig. 16, Fig. 17a-d, Fig. 18a-c, Fig. 19), the odds ratio was 0.59 , with a confidence interval of 0.35-0.99, which means that in the group of children treated early on by functional devices, the risk of trauma was $41 \%$ lower than that of patients treated in a single phase of treatment in adolescence.

\section{Does a two-phase treatment help prevent root resorption?}

The Cochrane systematic review on "Orthodontic treatment of prominent anterior maxillary teeth in children"66 concludes that, apart from the decrease in the prevalence of incisor trauma, there are no advantages to conducting treatment in two phases compared to a single-phase treatment in early adolescence.

This conclusion may surprise clinicians because of the positive correlations between the prevalence and severity of root resorptions, the importance of incisor apex displacement, and the duration of this displacement ${ }^{26,41,67}$.

A retrospective study ${ }^{11}$, certainly of lesser methodological value than the Cochrane systematic review ${ }^{66}$, compared the prevalence of incisor root

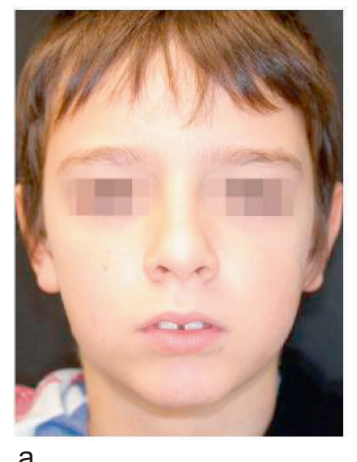

a

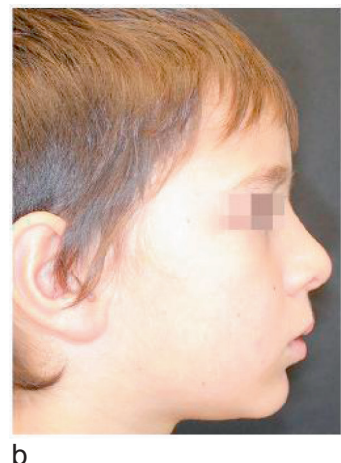

Figure 13 c

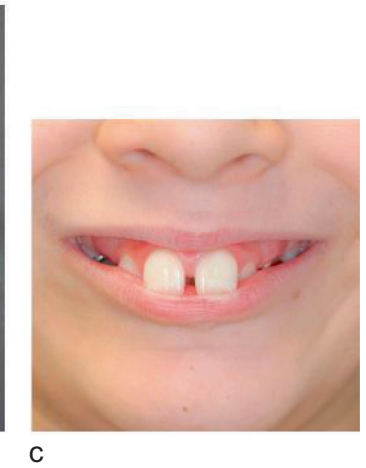

Case No. 3. Face (a), profile (b), and smile (c) portraits, before treatment. 


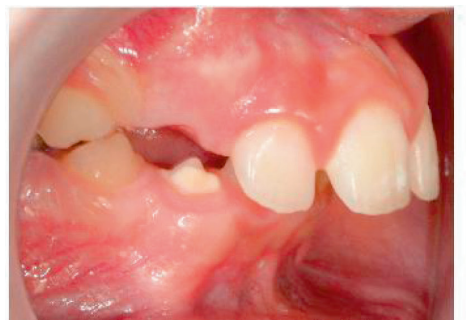

a

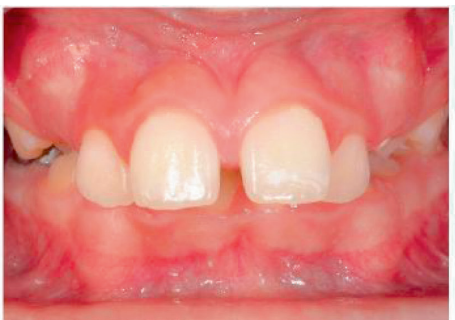

b

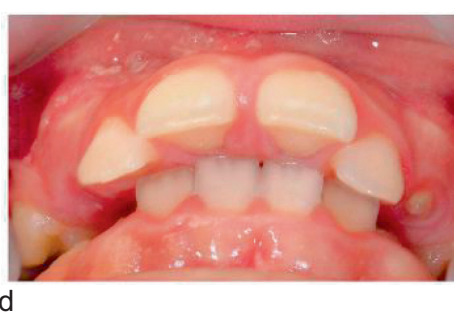

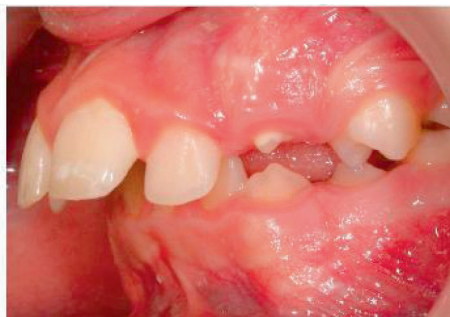

C

Figure 14

Right vestibular (a), frontal (b), Left (c), and low-angle (d) intraoral views before treatment. The patient, aged 9 years 7 months, has a Class-II, Division 1, with full canine Class-II and a 10-mm overhang. The first maxillary and mandibular molars were extracted for endodontic reasons.

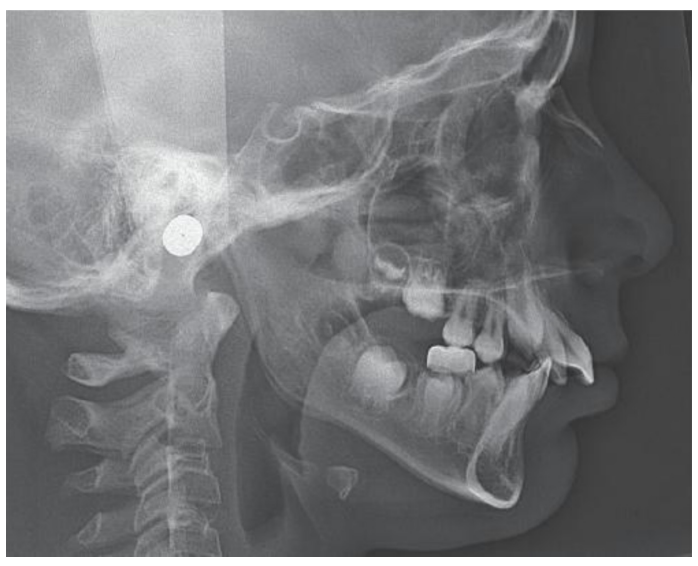

Figure 15

Profile teleradiography before treatment. The patient presents a skeletal Class-Il with a slight maxillary prognathism, a mandibular retrognathism, a short ramus and a short mandible.

resorptions after treatment in one or two phases.

These authors conclude:

- The existence of a significant association between external apical root

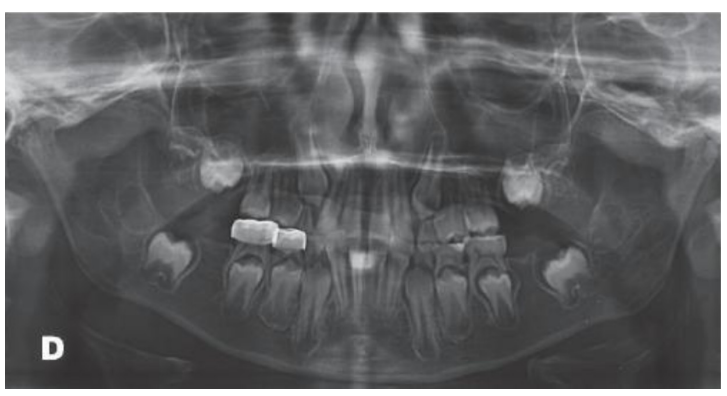

Figure 16

Panorama before processing. The absence of the first maxillary and mandibular molars, extracted for endodontic reasons, is noted.

resorption (EARR), amplitude of the incisor overhang reduction and duration of the multiattachment treatment phase;

- The possibility of decreasing the likelihood of EARR by performing an initial first stage of treatment, which decreases the magnitude of the overhang of Class-II malocclusions. 


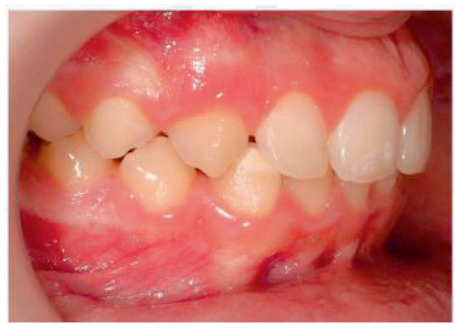

a
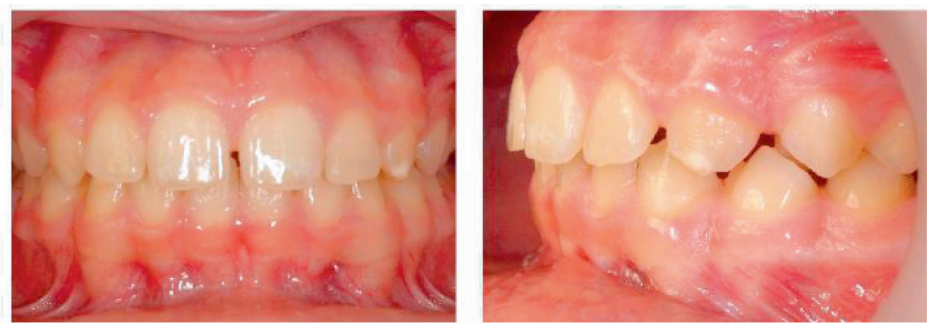

b

C

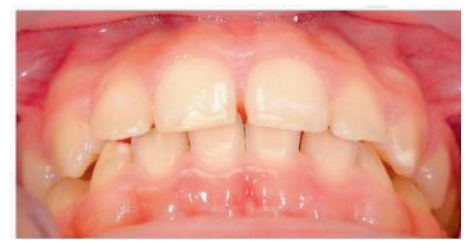

Figure 17

Right vestibular (a), front (b), Left (c), and low-angle (d) views, showing the correction obtained at the end of the first phase of the two-phase treatment (initial phase with maxillary harmonization by multibracket partial maxillary then Class-II corrector ${ }^{6}$, followed by a second phase with a bimaxillary and multibracket elasticated device.

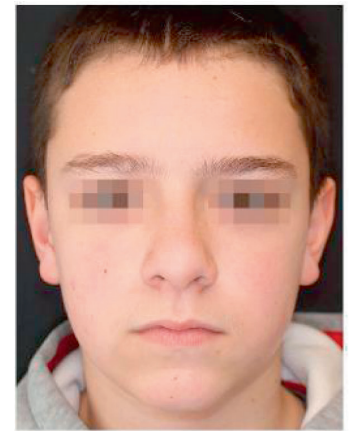

a

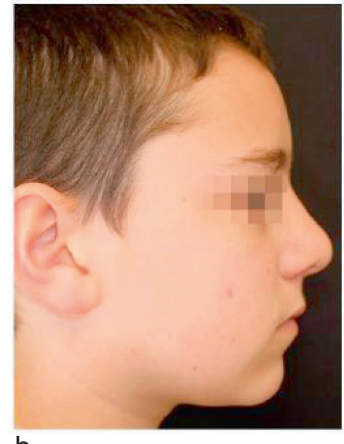

b

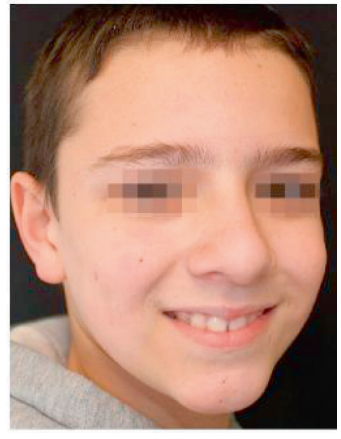

C

Figure 18

Face (a), profile (b), and three-quarter (c) portraits at the end of the first phase of the two-phase treatment.

The results of this study are particularly enlightening. A prevalence of EARR of $5 \%$ or $11 \%$ was observed in children treated in two phases, with a first phase conducted, respectively, by functional device or extraoral force. The treated patients, in a single phase with a multiattachment treatment, showed a prevalence of EARR of $20 \%$, which is 2-4 times higher.

An explanation, proposed by the authors, would be that in children who have benefited from a first phase of early treatment, the incisor overhang corrected with a multiattachment device was less significant. 


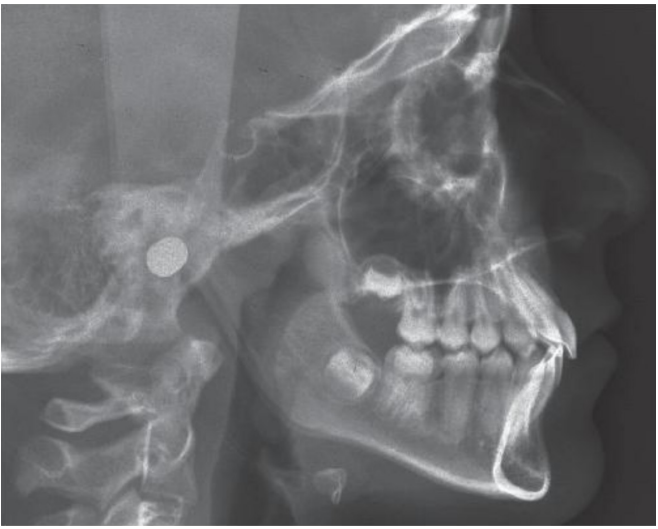

Figure 19

Profile teleradiography at the end of the first phase of the two-phase treatment.

It should be noted that the current absence of evidence, to which the Cochrane systematic review ${ }^{66}$ concludes, does not mean definitive evidence of absence. Clinicians can simply explain this to their patient and their family, make them benefit from their individual clinical competence
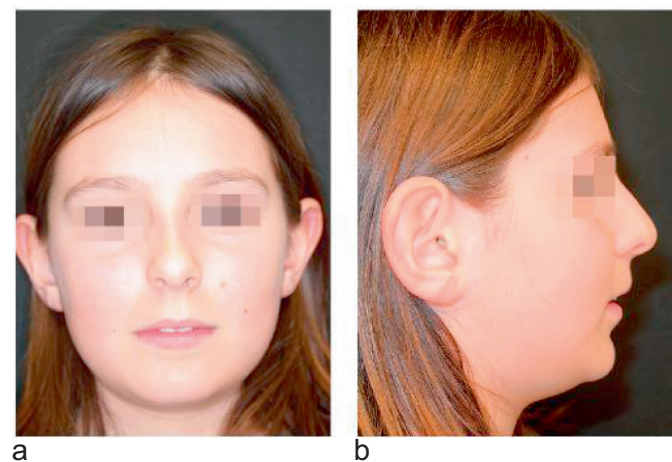

Figure 20

Case No. 4. Frontal (a) and profile (b) portraits before treatment.

and advise them of a first phase of treatment in case of increased incisor overhang (Fig. 20a and b, Fig. 21a-d, Fig. 22, Fig. 23a-d, Fig. 24a and b, Fig. 25), especially because marked risk factors of EARR are present. This mode of operation is precisely that of clinical decision making with the evidence-based orthodontics $(\mathrm{EBO})^{2,4}$.

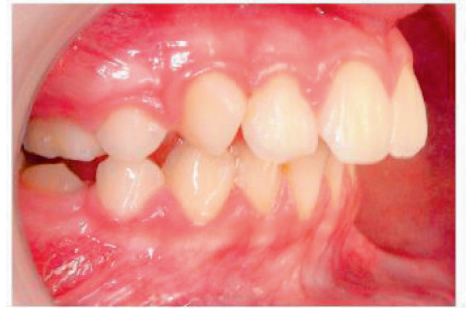

a

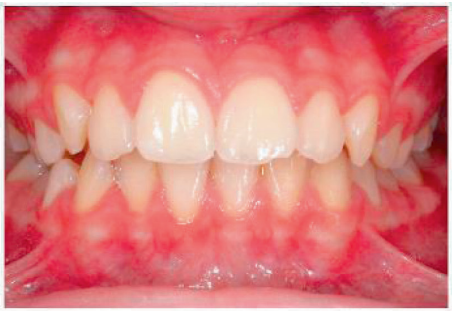

b

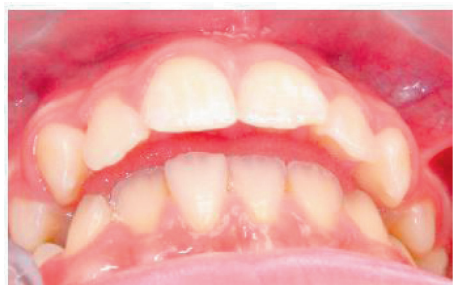

d

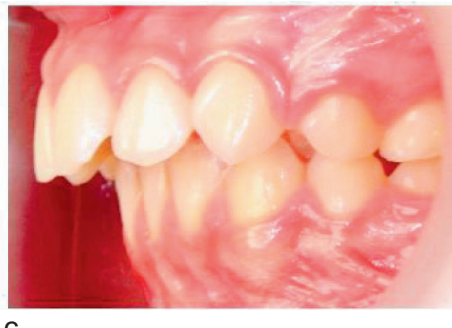

Figure 21

Right vestibular (a), front (b), left (c), and low-angle (d) intraoral views before treatment. The patient aged 10 years 5 months, has a Class-II, Division 1 malocclusion, with Class-II molar and canine malocclusions and an 8-mm overhang. 


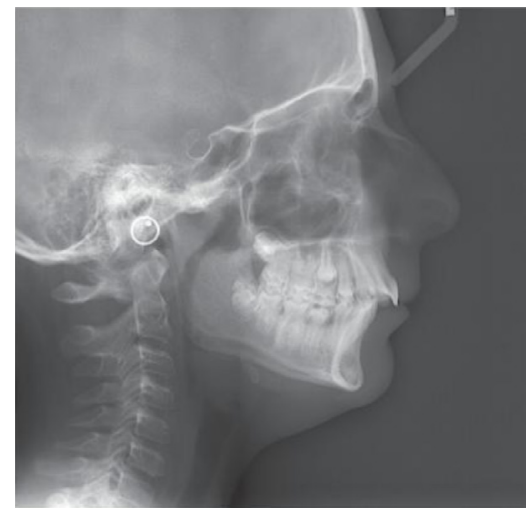

Figure 22

Profile teleradiography before treatment. The patient presents a skeletal Class II with maxillary prognathism and mandibular retrognathism.
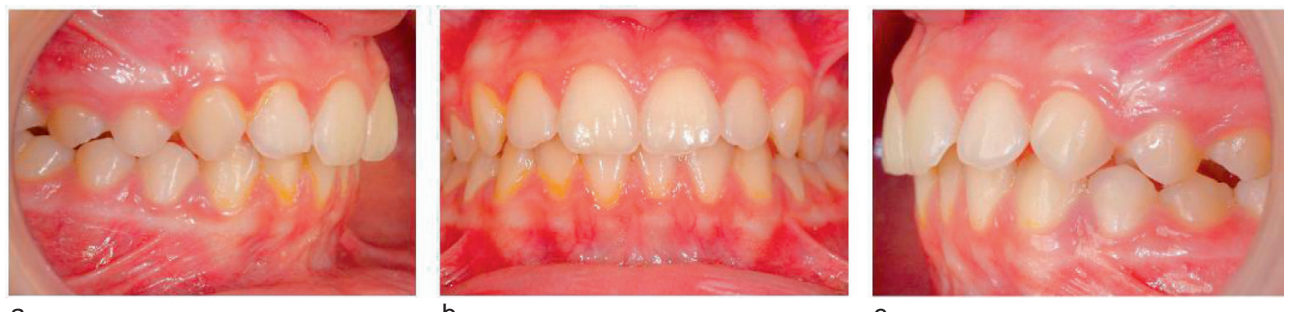

a

b

C

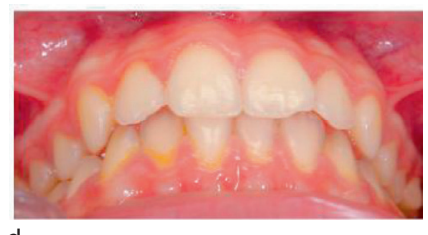

d

Figure 23

Right vestibular (a), front (b), left (c), and low-angle (d) intraoral views, showing the correction obtained at the end of the first phase, with quad-helix and a Class-II corrector ${ }^{6}$, of the two-phase treatment.

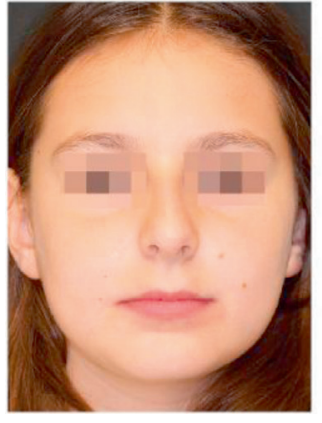

a

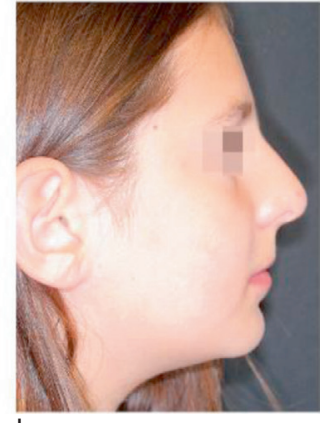

b

Figure 24

Face (a) and profile (b) portraits at the end of the first phase of a two-phase treatment. 


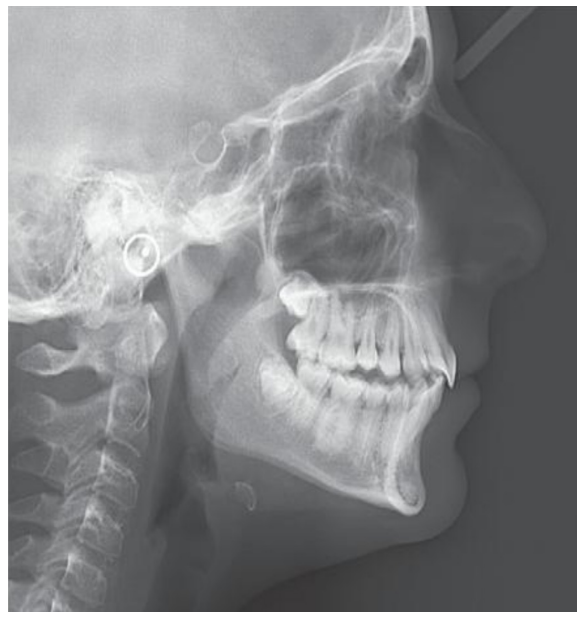

Figure 25

Profile teleradiography, at the end of the first phase of two-phase treatment.

\section{PARADIGM SHIFT IN THE TREATMENT OF CLASS-II MALOCCLUSIONS IN CHILDREN AND ADOLESCENTS}

The paradigm shift in clinical decision making, when taking into account the results of the best published data, has as a practical consequence, a paradigm shift in the treatment of Class-II malocclusions in children and teenagers.

\section{Abandonment of treatment of mandibular retrognathism by functional device}

Most patients with Class-II malocclusions exhibit mandibular retrognathism, rather than maxillary prognathism ${ }^{44,47}$. It seems medically relevant to target our therapeutic action on the precise cause of the dysmorphisms, and therefore to favor the reduction of the mandibular retrognathism. If the correction of a molar Class-II malocclusion and an incisor overhang does not pose any particular difficulties ${ }^{46}$ (Case no. 1 of Fig. 3-9), the correction of a mandibular retrognathism appears to be a more ambitious objective. Can it be achieved, with what device and therapeutic sequence? These questions are at the heart of a controversy that still exists in our profession.

The debate started in 1879, which saw the birth of functional treatments with Kingsley. At the beginning of the last century, Pierre Robin ${ }^{59}$ advocated clearing the vital crossroads by wearing a monobloc. This device achieves a transverse expansion of the arches and maintains the mandible and tongue in an advanced position. Its indication is the treatment of glossoptosis, a condition where mandibular retrognathism is just one of the symptoms.

In 1946, Brodie ${ }^{12}$ affirmed the genetic predetermination of irradiated and proportionate facial growth, according 
to a facial pattern. Orthodontic treatment cannot alter skeletal disharmony persists, without improving or worsening. Orthodontic treatments correct Class-II malocclusions only using dentoalveolar compensation, and have no skeletal effects. Although American orthodontists refute the role of functions on facial growth, European practitioners continue to use functional therapeutics.

The publication of the results of studies, on rats and macaques, by Pétrovic $^{54,64}$ and McNamara ${ }^{31,45}$ has revived the debate. They showed the possibility of an increase in mandibular length in these animals.

However, did these data offer any hope that treatment for mandibular retrognathism would be effective? Would it be possible to treat a skeletal Class-II malocclusion with a long-term increase in mandibular length, similar to that of orthognathic surgery? The enthusiasm raised by the publication of these studies was tempered by the level of evidence of studies in animals, classified as being on the lowest level of the pyramid hierarchy of facts $27,50,60$ (Fig. 26), and by the difficulty of a possible transposition of the experimental conditions in humans. It seems difficult to propose the permanent wearing of a hyperpropulsor for the whole duration of the patient's growth, such as with rats and monkeys, on which the studies were conducted.

Nevertheless, the thought was still firmly anchored that only a first phase of treatment by functional device allowed the orthopedic correction of a Class-II malocclusion, by modifying the direction and amount of mandibular growth.

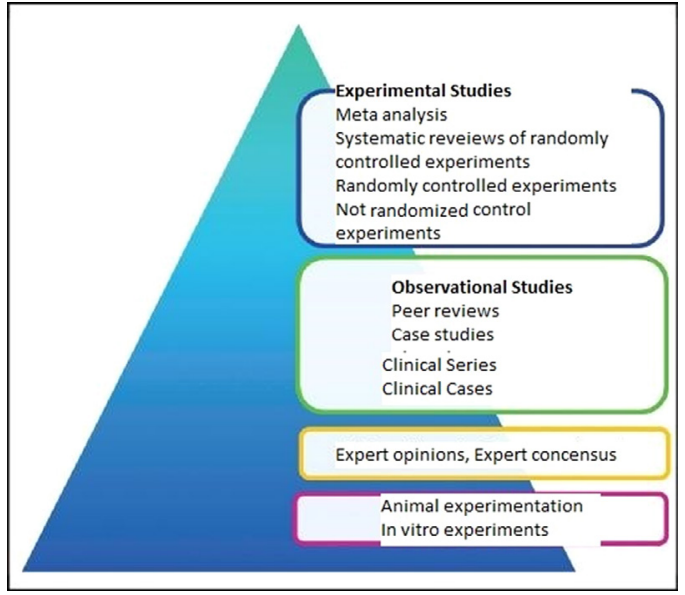

Figure 26

The hierarchy of facts $27,50,60$.

Since then, although many studies $^{22,46,51,71}$, systematic reviews ${ }^{20,52}$, and a recent Cochrane systematic review ${ }^{66}$, have shown the possibility of a shortterm increase in mandibular growth, they have also established that the effects of long-term skeletal treatment are weak and insignificant at best (Fig. 27a and b, Fig. 28a-c, Fig. 29, Fig. 30a-c, Fig. 31a-c, Fig. 32a-c, Fig. 33a and b, Fig. 34)

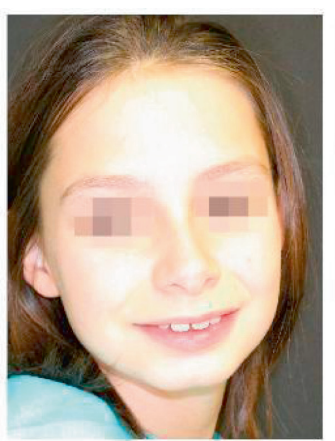

a

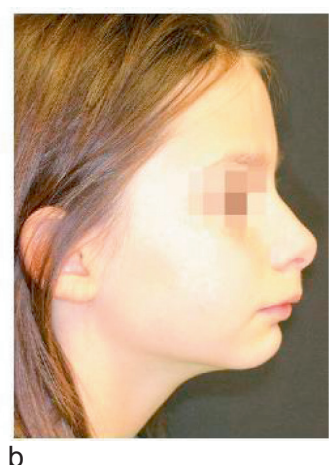

Figure 27
Case No. 5. Face (a) and profile (b) portraits, before treatment. 


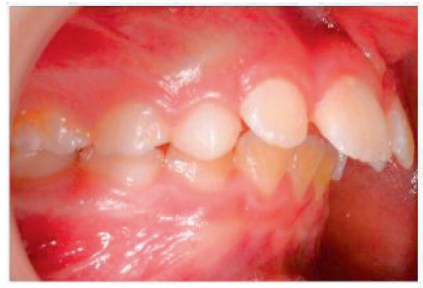

a

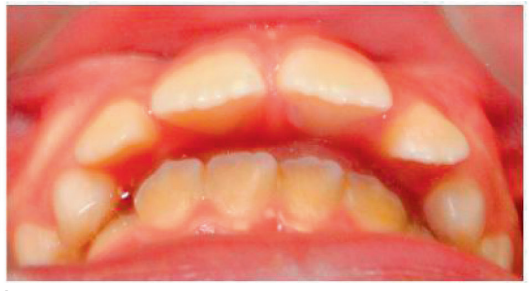

b

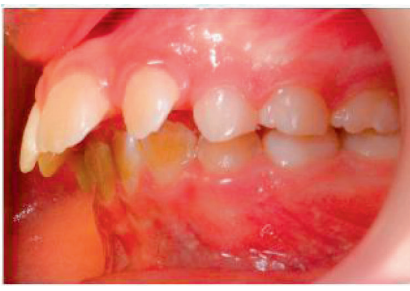

C

Figure 28

Right vestibular (a), low-angle (b), and left (c) intraoral views before treatment. The patient, aged 8 years 8 months, has a Class II, Division 1, with almost complete Class-II molar and canine and a 9-mm overhang.

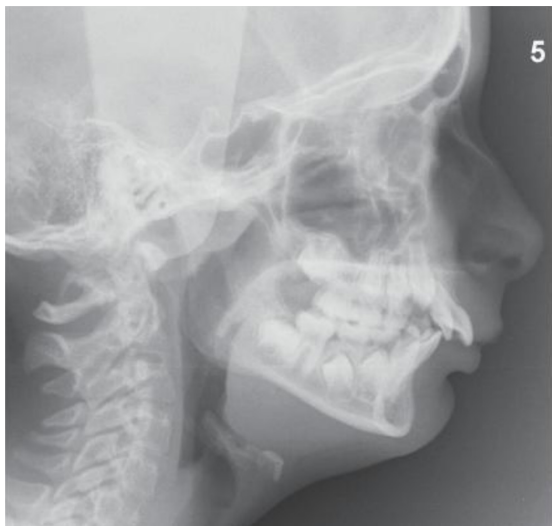

Figure 29

Profile teleradiography before treatment. The patient presents a skeletal Class II with maxillary prognathism, mandibular retrognathism, a decreased height of the lower section of the face, and a vestibuloversion of the mandibular incisors.

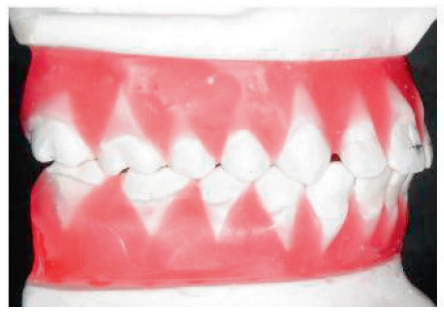

a

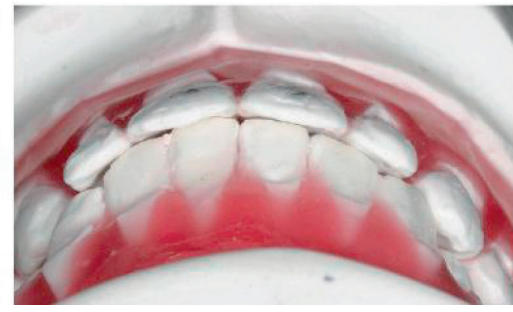

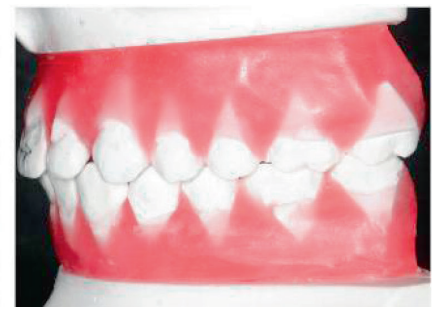

Figure 30

Right vestibular (a), low-angle (b), and left (c) views of the therapeutic setup, totally individualized, directed with an Articulator SAM II, having been used to manufacture the elasticated devices (Laboratoire France Élastodontie ${ }^{\circledR}$ ). The apparent dental disharmony defect is related to the demand for a slight hypercorrection of a Class I. 


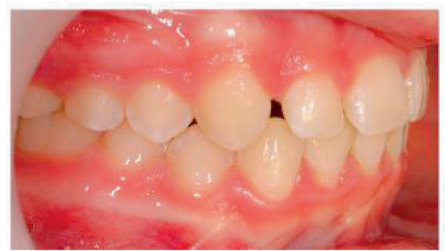

a

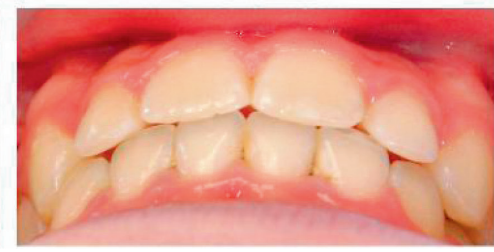

b

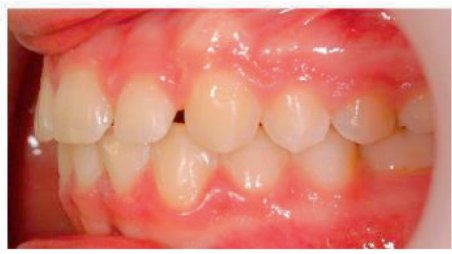

C

Figure 31

Right vestibular (a), low-angle (b), and left (c) intraoral views, showing the correction obtained at the end of the two-phase treatment, initially with quad-helix and a Class-II corrector $^{6}$, then with a bimaxillary multibracket device. The port of the elasticated device will allow the gradual adjustment of the occlusion and the attenuation of the diastema between the lateral and maxillary canine incisors.

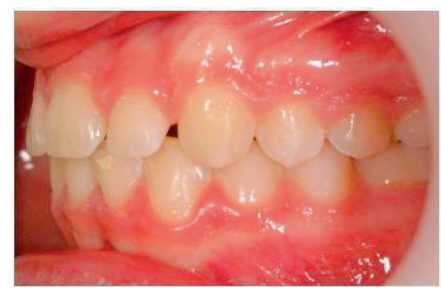

a

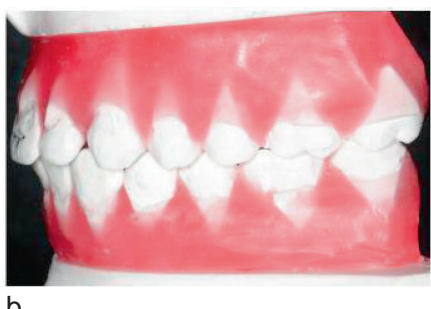

b

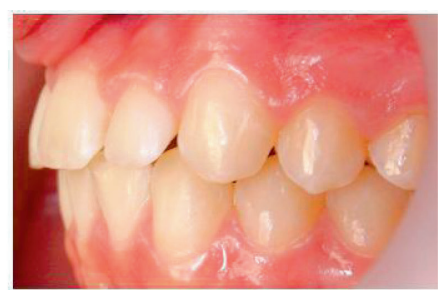

C

Figure 32

Right vestibular views of occlusion, end of multibracket treatment (a), therapeutic setup constructed with a slight hypercorrection of Class I (b), and occlusion obtained after wearing an elasticated device (c).

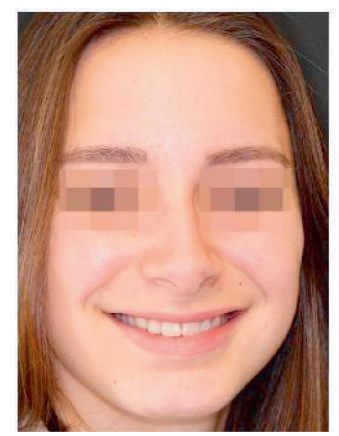

a

\section{Figure 33}

Face (a) and profile (b) portraits, at the end of the two-phase treatment.

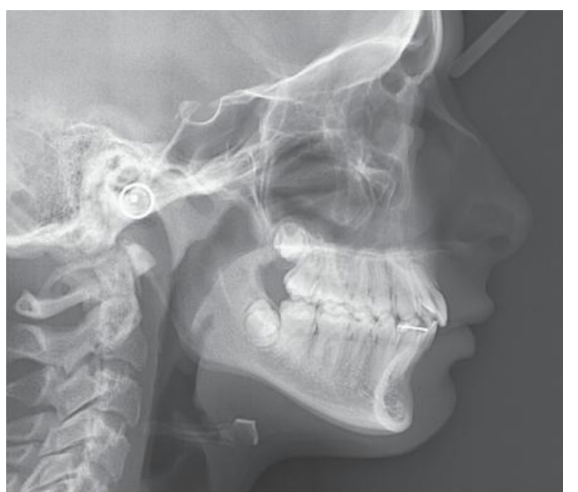

Figure 34

Profile teleradiography, at the end of the twophase treatment. The Class-II malocclusion was corrected and the mandibular incisors were slightly straightened. Skeletal Class II was attenuated, but the mandibular retrognathism was not fully corrected. 


\section{The end of the debate?}

It must be noted that the enthusiastic hypothesis of an effective cure for mandibular retrognathism has given way to a false hope, which has been invalidated, publication after publication, by factual data.

Why have we not closed this debate? Why have we not yet completely changed the treatment paradigm? Why are we still talking about a treatment for mandibular retrognathism, and not, simply, a correction of a Class-II malocclusion? Some of the explanations can be found in simple facts:

- One is the persistence of the erroneous belief that multiattachment devices, unlike functional devices, can only treat a Class-II malocclusion with dentoalveolar compensation, and possibly by maxillary retraction when the treatment is coupled with the use of an extraoral force;

- Another is the apparent stability of Class-II malocclusions, which, if untreated, do not appear to be mitigated by growth ${ }^{19,38}$. This widespread clinical observation casts doubt on the clinicians' mistaken belief that mandibular growth may make a favorable contribution to Class-II correction.

- These facts do not in any way challenge the published data and the aforementioned conclusion of the debate. They are simply explained by the phenomenon of dentoalveolar compensation ${ }^{42,63}$

\section{The dentoalveolar compensation phenomenon}

Björk and Skieller have shown that, for most patients, mandibular growth is greater than maxillary growth ${ }^{10}$. This maxillofacial growth differential does not depend on the initial Angle Class - it is observed, both in Class-I and Class-II patients ${ }^{39}$.

Other authors ${ }^{9,34}$ have confirmed the existence of this differential of maxillomandibular growth differential, which is favorable to the skeletal correction of Class-II malocclusions, whether or not a Class-II treatment is applied.

In a Class-II patient, in the absence of treatment, occlusal meshing and labial-lingual interposition, prevent the excess of mandibular growth from participating in the correction of the Class-II occlusion?.

This excess mandibular growth leads, in fact, to a mesialization of the maxillary dental arch, giving the clinical illusion that growth has no effect on Class-II patients. This is the phenomenon of dentoalveolar compensation $^{42,63}$. On average, the maxillary dental arch is mesial by an amount equal to the excess mandibular growth ${ }^{34}$.

In a Class-II patient, if functional therapy is applied, the mandible is maintained in Class-I occlusion, while a growth catchup ${ }^{35}$ eliminates the occlusion of convenience induced by the therapy. This catching up of growth occurs without any maxillary dentoalveolar compensation ${ }^{38}$. The functional device prevents the maxillary arch from advancing.

In a Class-II patient, if a single-phase multibracket treatment is applied, the belief persists that this treatment cannot improve skeletal shift. In fact, in this case too, the growth of the mandible exceeds that of the maxilla. For example, nine times out of 10 in a study by Johnston LE Jr ${ }^{36}$, who writes that it is necessary to "give Caesar what is Caesar's" and recognize the involvement of the different maxillomandibular growth 
in the correction of Class-II malocclusions, regardless of the treatment device used.

\section{Which Class-II malocclusion treat- ment, is most appropriate for a child or adolescent individual?}

The daily clinical experience of practitioners shows that the correction of a Class-II shift in children and adolescents can be effectively achieved through a large number of therapeutic modalities. They vary from the use of functional devices ${ }^{1}$, possibly associated with auxiliaries ${ }^{40}$, to orthognathic surgery, including, among others, the distalization of the maxillary arch with the use of extraoral or bone anchors or compensatory extractions.
However, a treatment process, for example the one chosen for the case No. 1 (Fig. 3-9), can certainly be effective, but was it the most appropriate? Was it the one which best met our therapeutic objectives and the concerns and preferences of our patient and their family?

Answering this question requires defining individual decision-making factors in the patient's specific case. This description would require development that is inconsistent within the limited scope of this article. Our main current clinical decision-making factors-anatomical, risk, psychosocial and external factors-are grouped together in a diagram (Fig. 35).

We will limit ourselves to addressing a few clinical issues and cases, which would enable us to illustrate

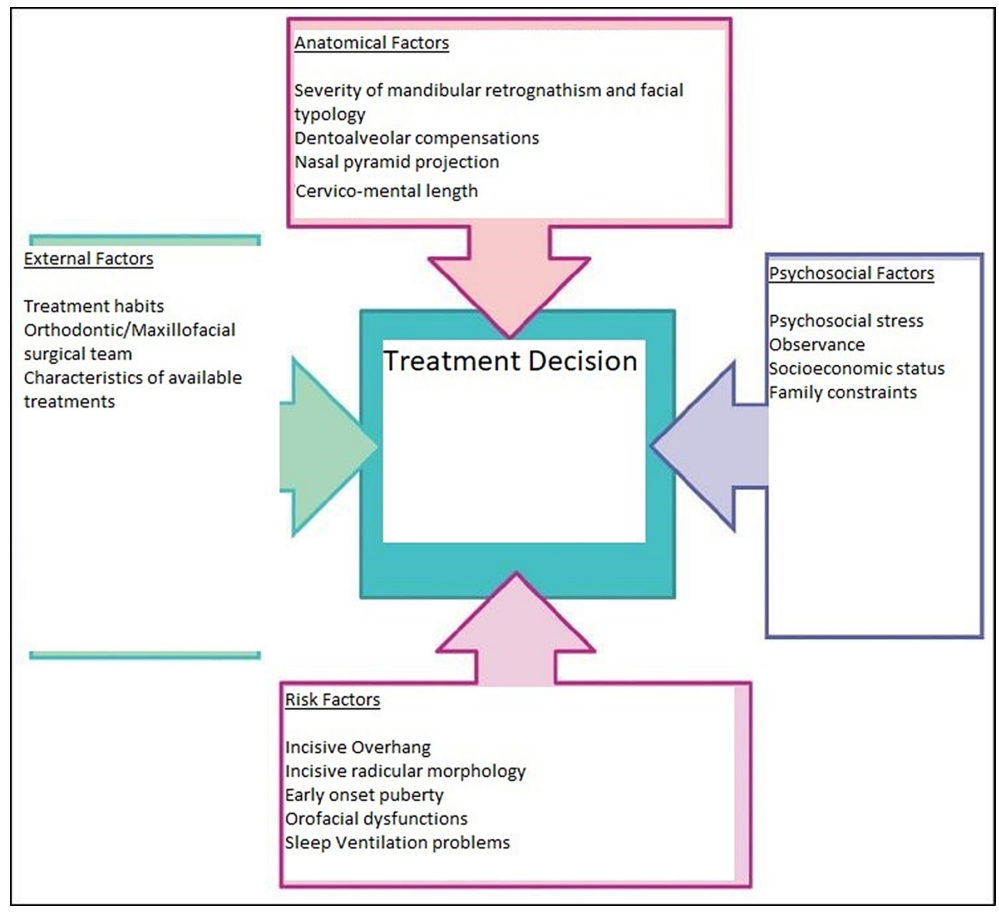

Figure 35

Key factors in clinical decision making for the treatment of Class-II malocclusions in children and adolescents. 
the paradigm shift in the treatment of Class-II malocclusions in children and adolescents.

\section{Maxillary prognathism or mandibular retrognathism: the same treatment?}

Even if the disillusion is great, it is necessary to accept the conclusions of the published data $22,46,51,71,20,52,66$. For most children and adolescents with Class-II malocclusions, mandibular growth will be clinically similar, whether or not these patients are treated ${ }^{7}$ with functional devices or multiattachments with or without the use of extraoral or bone anchors or compensatory extractions.

It does not matter, then, that Class-II malocclusions are mainly dental or skeletal and show signs of maxillary prognathism or mandibular retrognathism, our therapeutic field of action is ultimately almost the same ${ }^{36}$.

For example, if a skeletal Class II is related to maxillary prognathism, the use of a functional device (Fig. 36a-c, Fig. 37a-d, Fig. 38, Fig. 39a-d, Fig. 40a-d, Fig. 41a-c, Fig. 42) is as relevant as that of an orthopedic device to inhibit maxillary growth. first maxillary molars, extracted for endodontic reasons), and a Class-II corrector ${ }^{6}$.

Case No. 7 (Fig. 43), less favorable, was treated with a bimaxillary multiattachment and elasticated device. He required the extraction of the second maxillary premolars seconds and the first mandibular premolars, and orthognathic surgery, with an Epker advanced mandible, and a height reduction and projection genioplasty.

This data does not exempt clinicians from the delicate appreciation of the mandibular growth potential| ${ }^{17,21}$ and the possible need for orthognathic surgery.

Cases 1, 2, 3, 4, 5, and 6, had skeletal Class-II malocclusions with various characteristics, respectively:

- Case 1: Maxillary prognathism, mandibular retrognathism, and anterior vertical deficiency;

- Case 2: Maxillary prognathism and mandibular retrognathism;

- Case 3: A slight maxillary prognathism, a mandibular retrognathism, a short ramus, and a short mandible;

- Case 4: Maxillary prognathism and mandibular retrognathism;

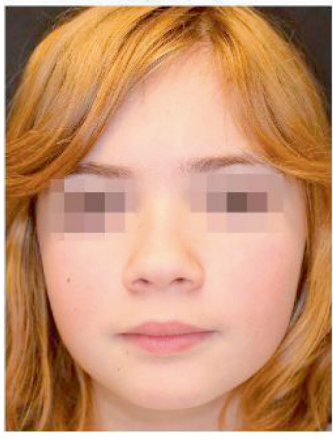

a
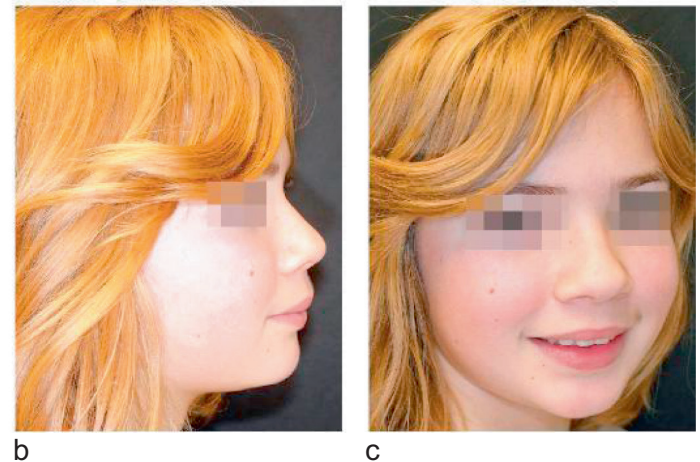

C

Figure 36

Case No. 6. Face (a), profile (b), and three-quarter (c) portraits before treatment. 

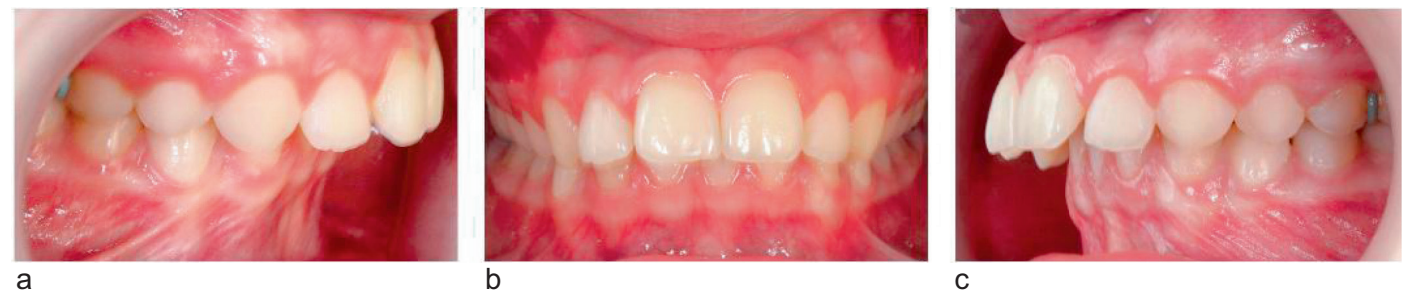

a

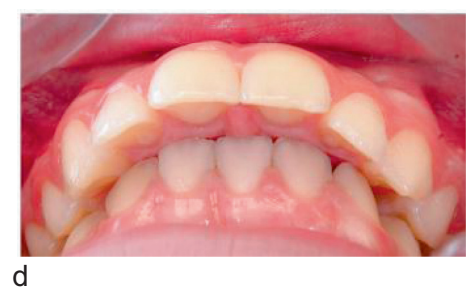

Figure 37

Right vestibular (a), frontal (b), left (c), and low-angle (d) views before treatment. The patient, aged 9 years 5 months, has a Class-II, Division 1 malocclusion, with Class-II molar and canine malocclusions, an 8- $\mathrm{mm}$ overhang and the agenesis of a mandibular incisor.

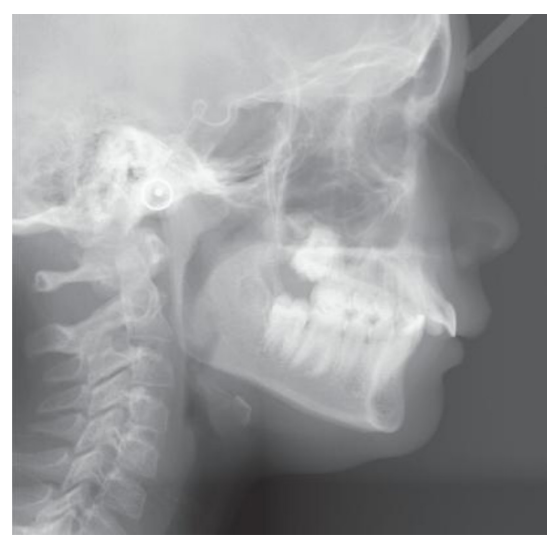

Figure 38

Profile teleradiography before treatment. The patient presents a skeletal Class-II malocclusion with maxillary prognathism, and a slight anterior vertical deficiency.

- Case 5: A maxillary prognathism, a mandibular retrognathism, a decreased height of the lower section of the face, and a vestibuloversion of the mandibular incisors;
- Case 6: A maxillary prognathism and a slight anterior vertical insufficiency. They all benefited from a first phase of treatment, with a quad-helix (or partial maxillary multibracket for case 3, because of the absence of (a) (b). 


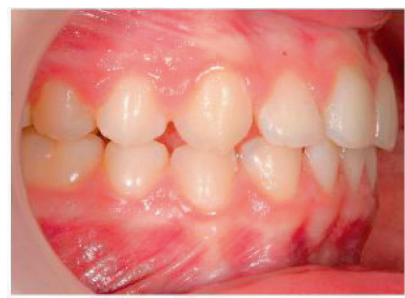

a

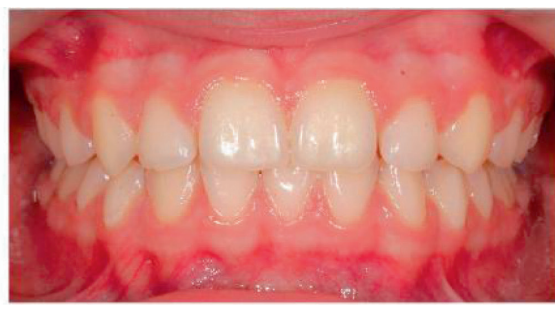

$\mathrm{b}$

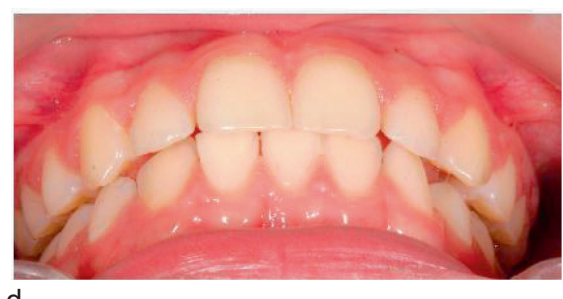

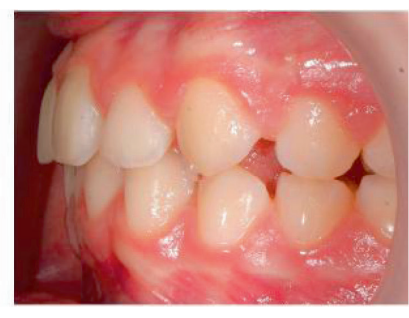

C

Figure 39

Right vestibular (a), front (b), left (c), and low-angle (d) intraoral views, showing the correction obtained at the end of the first phase of treatment with a quad-helix and a Class-II corrector ${ }^{6}$

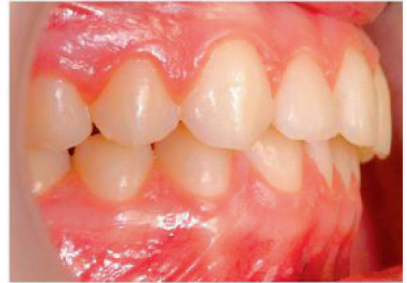

a

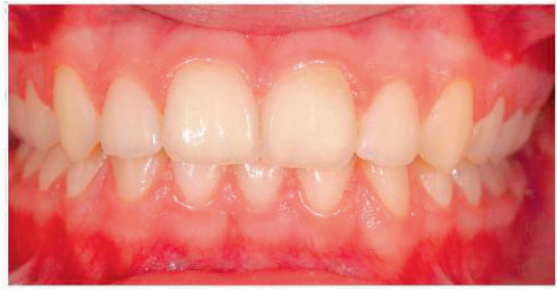

b

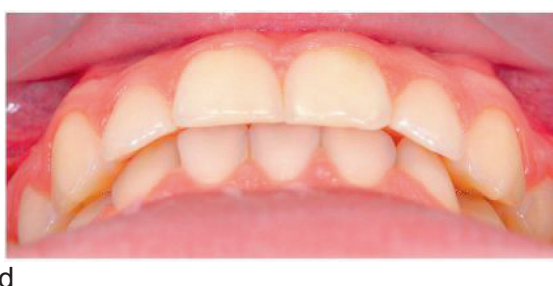

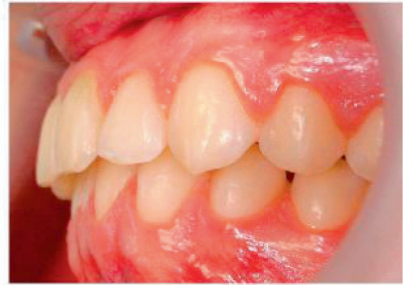

C

Figure 40

Right vestibular (a), front (b), left (c), and low-angle (d) intraoral views, showing the malocclusion before the second treatment phase, orthodontics with bimaxillary and elasticated multibracket device. The incisive movement, incisor overhang and covering, which have appeared since the end of the first stage of treatment, are linked to the agenesis of a mandibular incisor. The patient did not want to undergo the second stage of treatment. 


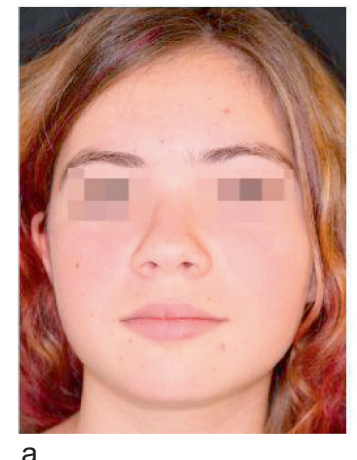

a

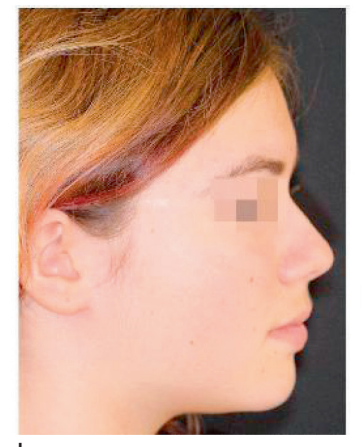

b

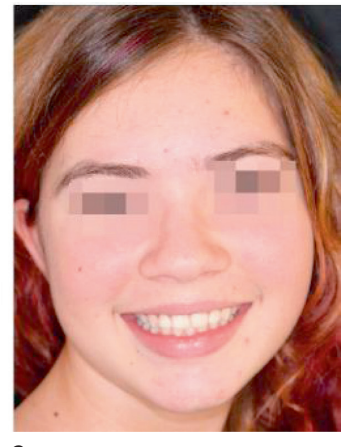

C

Figure 41

Face (a), profile (b), and three-quarter (c) portraits at the end of the first orthopedic treatment phase.

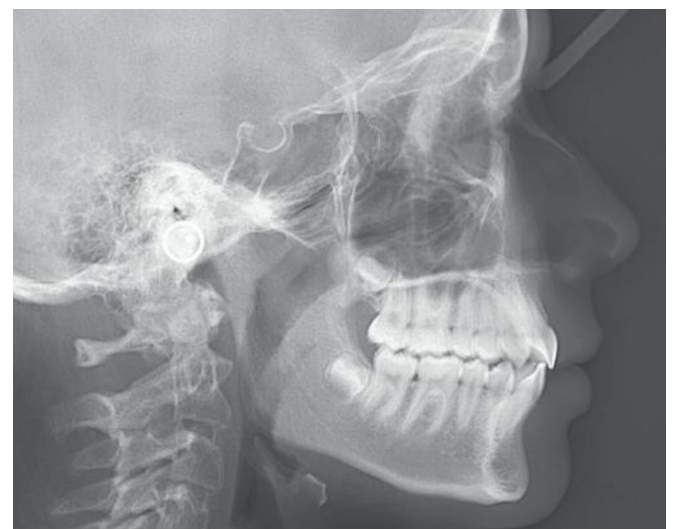

Figure 42

Profile teleradiography, at the end of the first phase of treatment.

\section{What treatment objectives should be given priority?}

Abandoning the objective of a perennial increase in mandibular length, allows us to refocus the treatment on the achievement of other therapeutic objectives.

Depending on the individual case of the patient, clinicians may, in particular, aim to decrease the risk of trauma of the maxillary incisors ${ }^{66}$, decrease the risk of root resorptions ${ }^{62}$, improve the quality of life ${ }^{24}$, increase the volume of
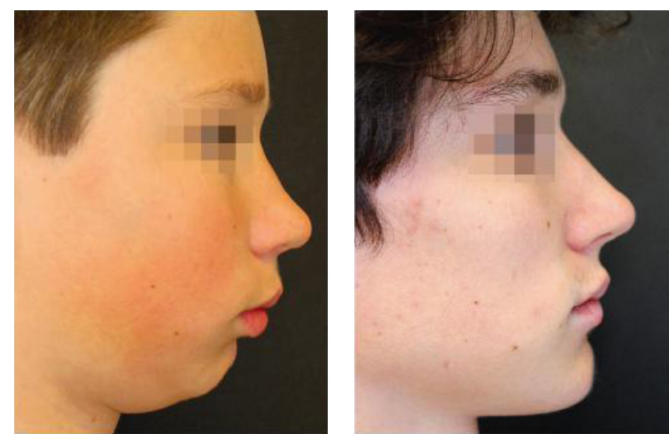

Figure 43

Case No. 7. Profile Portraits before (a) and after (b) treatment. The multiattachment treatment was associated with the extraction of 15,25,34,44, and orthognathic surgery (Epker advanced mandible and genioplasty to decrease the height and projection, performed by Dr. Y. Heuzé).

the airways $32,58,68,70$, and improve any obstructive sleep disorders ${ }^{14,30,65}$.

\section{Which treatment device should you choose?}

All Class-II treatment devices, including, functional devices, intermaxillary elastics, extraoral forces and temporary bone-anchoring devices, have no 
overall influence, better or worse, on the mandibular growth response.

If the choice of one of these devices is therefore neutral in respect to increasing mandibular length, it is not neutral with respect to other elements, such as the risk of the appearance of unstable dentoalveolar compensations. The strength and cost of the device, its ease of implementation, and its acceptance by the patient should also be considered.

It is clearly no longer the case today that clinicians would propose a more restrictive device or a device which is more difficult to implement when trying to find a cure for mandibular retrognathism.

They are now free, when proposing to the patient the various therapeutic approaches, to privilege, with pragmatism and common sense, the other criteria of choice.

With the exception of case 7 , treatments in all cases presented in this article involved a first stage of treatment with a functional device, i.e., Class-II corrector $^{6}$.
Class-II correctors are preferred for the early stage of treatment (Fig. 44a-C, Fig. 45, Fig. 46a-c, Fig. 47), and also for later treatments, such as those used in case No. 9 (Fig. 48a and b, Fig. 49a-d, Fig. 50, Fig. 51a-d, Fig. 52a and b, Fig. 53).

The patient, aged 13 years 5 months, was being transferred from one orthodontic practice to another, following a shift in residence. He had a Class-II, Angle 1 Division 1 malocclusion with a $10-\mathrm{mm}$ overhang on a Class-II skeletal pattern, with mandibular retrognathism, vestibuloversion of the mandibular incisors, and anterior vertebral insufficiency.

He refused surgery, which had been planned by the previous orthodontist, and wanted to stop wearing the multiattachment device. Following the presentation to the patient and their family about the diagnosis, the various treatment options, including the complete cessation of treatment at his request, the benefits and risks of these options, the patient agreed to try treatment with a functional device. He observed

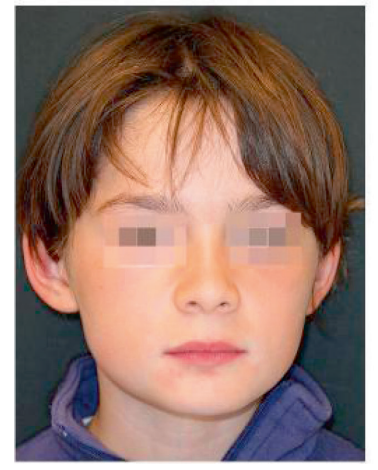

a

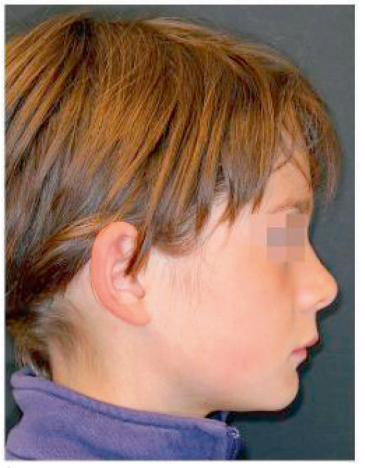

b

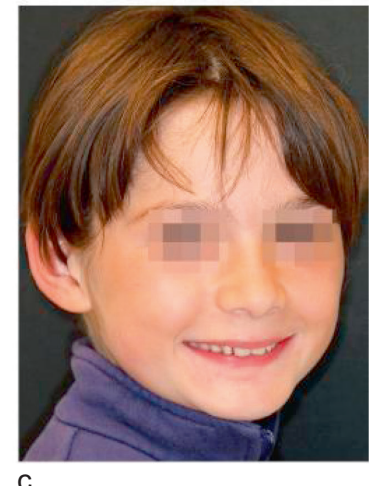

C

Figure 44

Case No. 8. Face (a), profile (b), and three-quarter (c) portraits before treatment. The patient, aged 9 years 4 months, has a Class-II, Division, with full molar and canine Class II and an 8-mm overhang. 


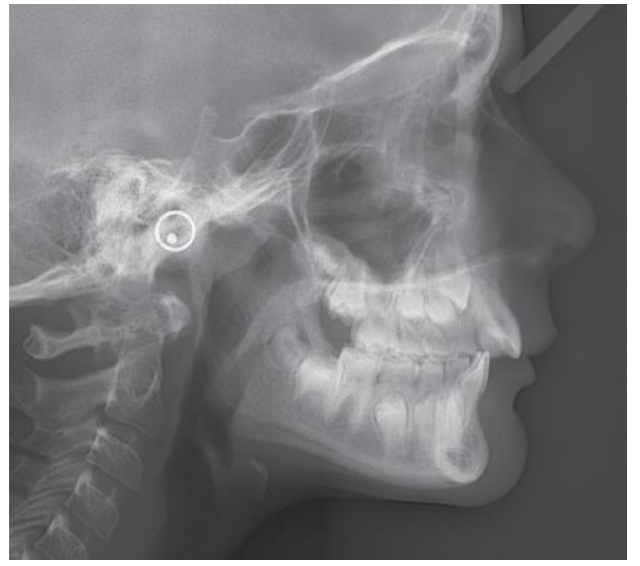

Figure 45

Profile teleradiography, before treatment. The patient presents a skeletal Class-II malocclusion with a slight maxillary prognathism and mandibular retrognathism.

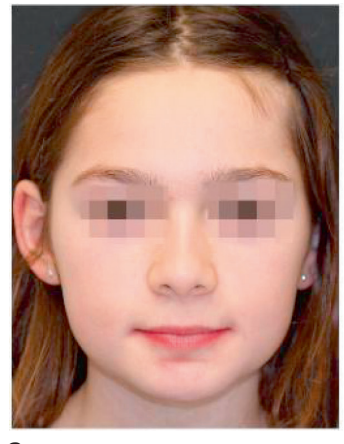

a

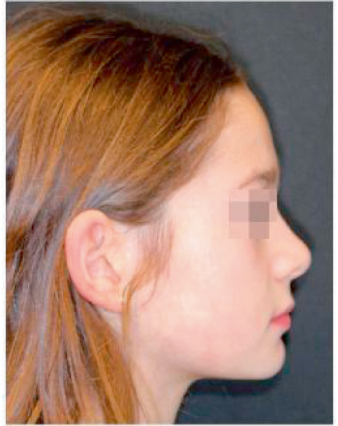

$\mathrm{b}$

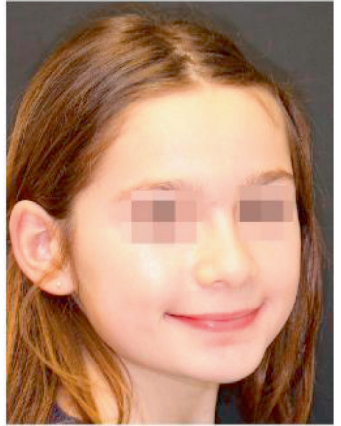

C

Figure 46

Face (a), profile (b), and three-quarter (c) portraits at the end of the first treatment phase.

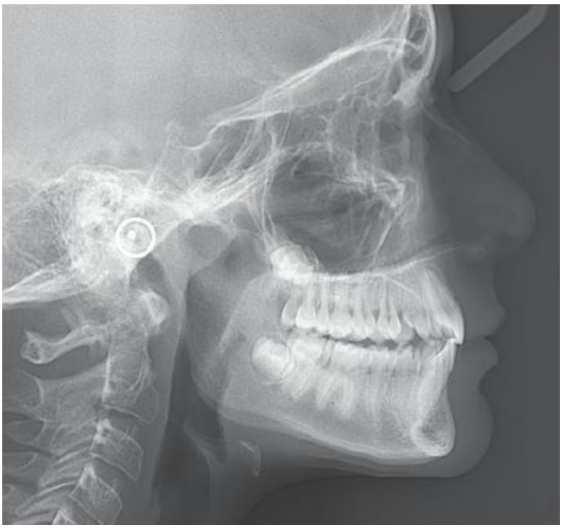

Figure 47

Profile teleradiography, at the end of the first phase of treatment.

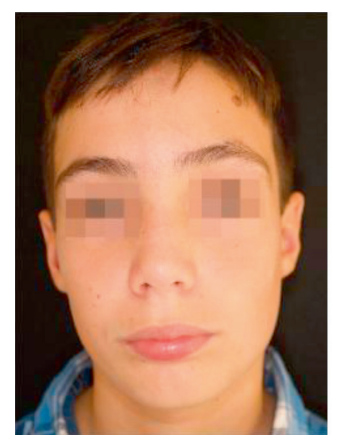

a

b

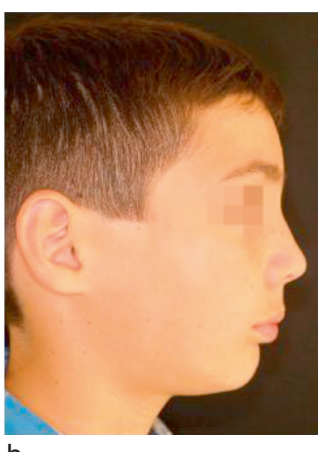

Figure 48

Case 9. Face (a) and profile (b) portraits, before resuming treatment following a transfer. 

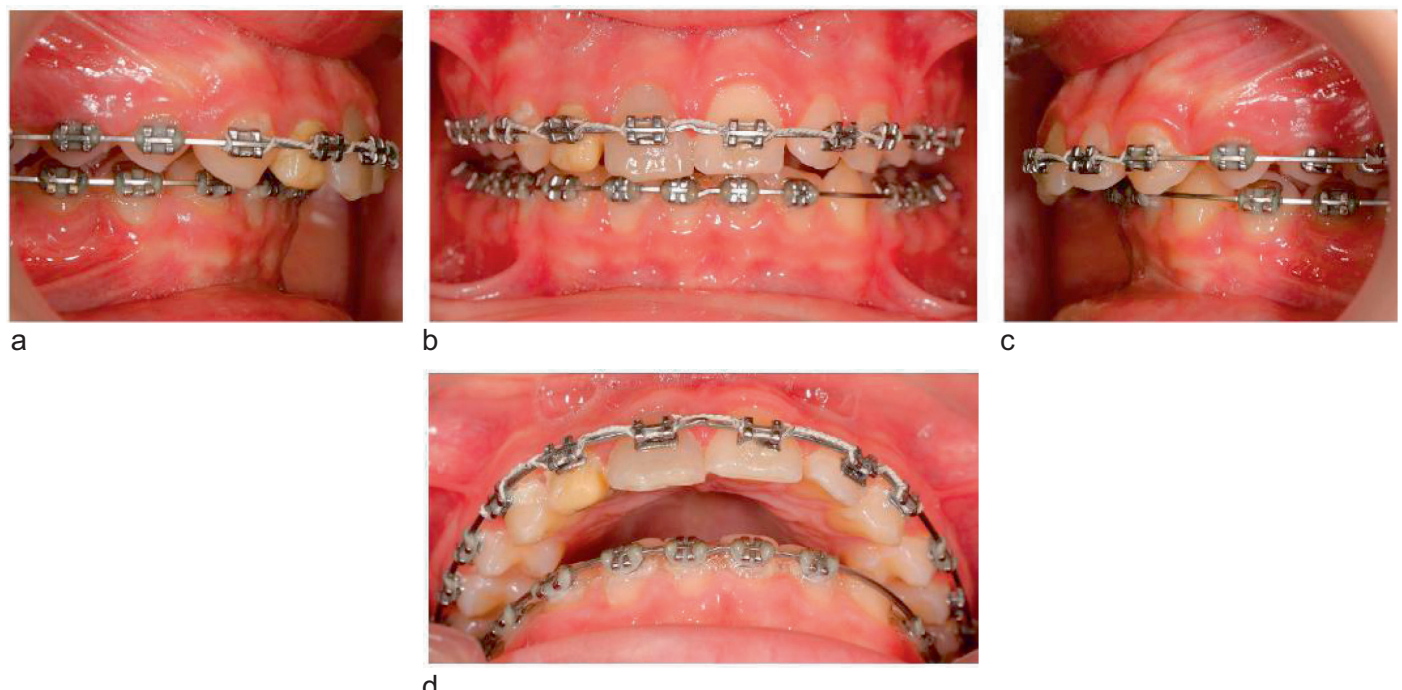

Figure 49

Right vestibular (a), front (b), left (c), and low-angle (d) intraoral views, before resuming treatment after a transfer. The patient, aged 13 years 5 months, has a Class II, Division 1 , with full molar and canine Class II and a 10- $\mathrm{mm}$ overhang (note that the 11 is devitalized).

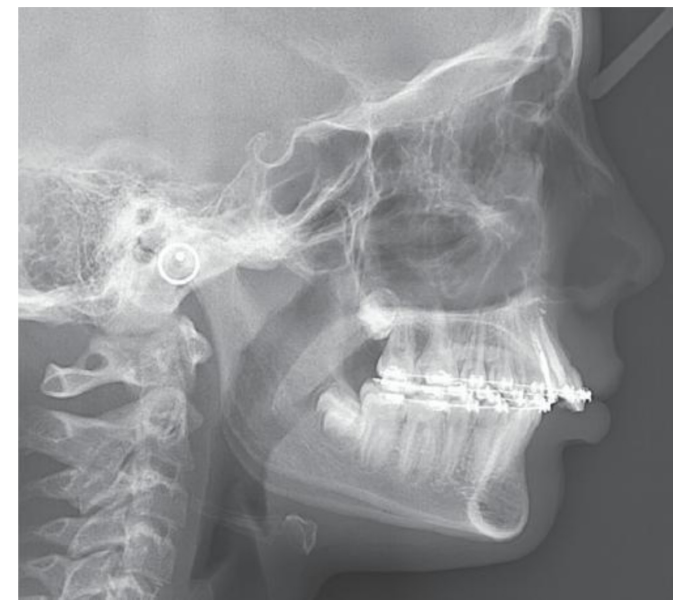

Figure 50

Profile teleradiography, before resuming treatment. The patient exhibits skeletal Class II with mandibular retrognathism, vestibuloversion of mandibular incisors, and anterior vertical deficiency.

the procedure and wore the Class-II corrector ${ }^{6}$ for 6 months, put in place after the removal of the multiattachment device. He does not envisage any other treatment if the result obtained remains stable. 


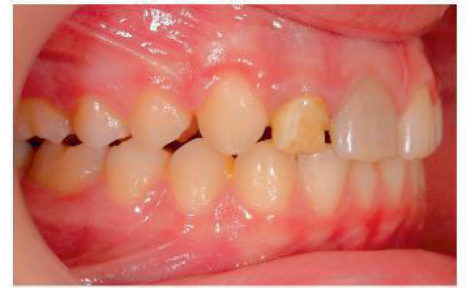

a

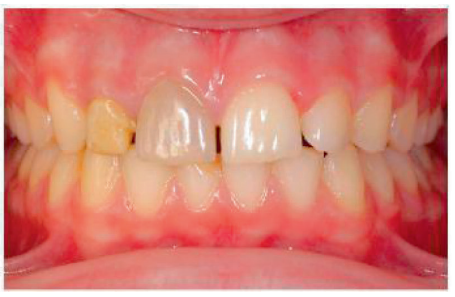

b

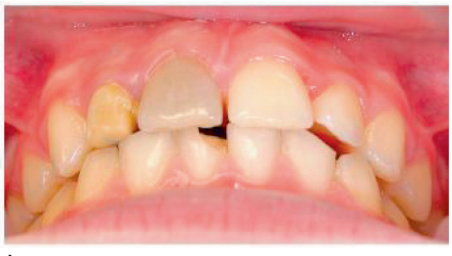

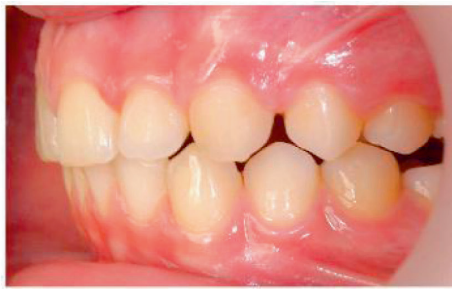

C

Figure 51

Right vestibular (a), front (b), left (c), and low-angle (d) intraoral views taken at the end of the treatment with Class-II corrector ${ }^{6}$. This was performed for 6 months, after removal of the multiattachment device worn by the patient when he was transferred.

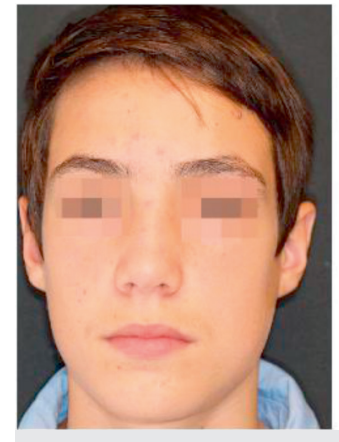

a

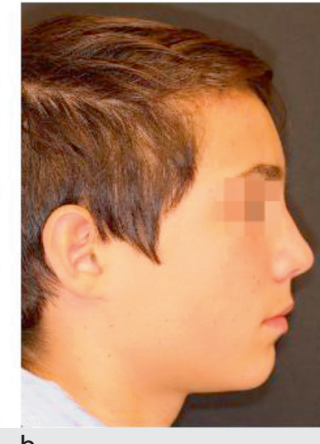

b

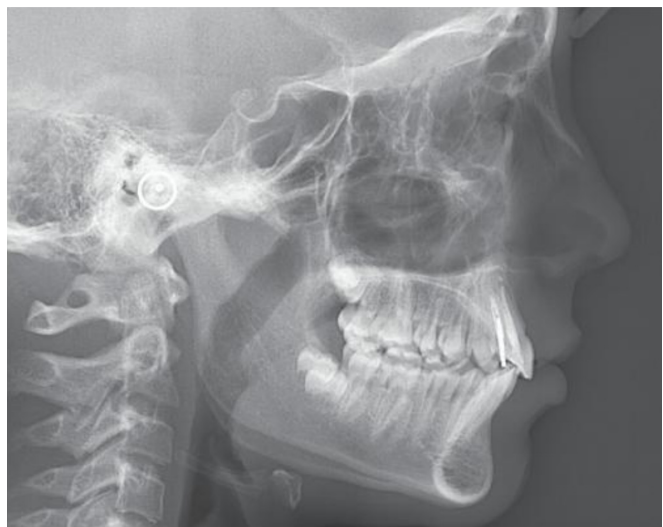

Figure 53

Profile teleradiography taken at the end of treatment with a Class-I/ corrector ${ }^{6}$

\section{CONCLUSION}

The future feeds on the past. With his customary humor, J. Philippe wrote how effective orthodontics practiced in the 1960s was ${ }^{57}$. For example,
Mrs. Tacail described a mandibular advance of $1 \mathrm{~cm}$ as a regression. The subsequent introduction of teleradiography and cephalometric overlay 
techniques has showered enthusiasm on this generation of clinicians, while providing them with the progress of a better understanding of their real treatment possibilities.

EBO has also been, and is, a source of scientific and clinical progress. To discover that the long-term skeletal effects of a first phase of treatment, are, at best, weak and clinically insignifi- cant $20,52,66$, was a bitter disappointment for our profession. But this new data has also enabled a therapeutic evolution, a beneficial paradigm shift toward a more appropriate treatment of Class-II malocclusions to the individual patient case of a child or adolescent.

Conflict of interest: The author states that there is no conflict of interest.

\section{BIBLIOGRAPHY}

1. Amat P. Contribution of a functional and orthopaedic splint to the treatment of Class II malocclusions. 103rd Annual Session of the American Association of Orthodontists; Honolulu, Hawaii, May 26, 2006.

2. Amat P. What would you choose: evidence-based treatment or an exciting, risky alternative? Am J Orthod Dentofacial Orthop. 2007;132:724-5.

3. Amat P. L'orthodontie fondée sur les faits: aussi simple que de compter 1, 2, 3. L'Orthodontie Bioprogressive. 2011;19:45-52.

4. Amat P. Dentisterie fondée sur les faits: en omnipratique et en orthodontie. Paris: Éditions CdP, 2012.

5. Amat P. À la recherche d'un équilibre dans les décisions thérapeutiques. L'exemple du traitement des Rev Orthop Dento Facial 2017; 51:49-91. malocclusions de classe II chez I'enfant et l'adolescent. Orthod Fr. 2016;87:375-92.

6. Amat P. Traitement des malocclusions de classe II chez l'enfant et l'adolescent: I'apport du Correcteur de classe II. Orthod Fr. 2017. Accepté pour publication.

7. Bishara SE. Mandibular changes in persons with untreated and treated Class II Division 1 malocclusion. Am J Orthod Dentofacial Orthop. 1998;113:661-73.

8. Bishara SE, Hoppens BJ, Jakobsen JR, Kohout FJ: Changes in the molar relationship between the deciduous and permanent dentitions: a longitudinal study. Am J Orthod. 1988;93:19-28.

9. Bishara SE, Jakobsen JR, Vorhies B, Bayati P. Changes in dentofacial structures in untreated Class II division 1 and normal subjects: A longitudinal study. Angle Orthod. 1997;67:55-66.

10. Björk A, Skieller V. Croissance mandibulaire normale et pathologique. Synthèse d'études céphalométriques ongitudinales à l'aide d'implants, sur une période de 25 ans. Rev Orthop Dentofac. 1984;18:9-63.

11. Brin I, Tulloch JF, Koroluk L, Philips C. External apical root resorption in Class II malocclusion: a retrospective review of 1-versus 2-phase treatment. Am J Orthod Dentofacial Orthop. 2003;124:151-6.

12. Brodie AG. Facial Patterns: A theme on variation. Angle Orthod. 1946;16:75-87. 
13. Burden DJ. An investigation of the association between overjet size, lip coverage, and traumatic injury to maxilary incisors. Eur J Orthod. 1995;17:513-17.

14. Carvalho FR, Lentini-Oliveira DA, Prado LBF, Prado GF, Carvalho LBC. Oral appliances and functional orthopaedic appliances for obstructive sleep apnoea in children. Cochrane Database of Systematic Reviews 2016, Issue 10. Art. No.: CD005520. DOI: 10.1002/14651858. CD005520.pub3.

15. Chateau M. Orthopédie Dento-Faciale. Masson. Prélat éd., Paris, 1964.

16. Chateau M, Le Gall Y. Appareillages amovibles pour Classes II. Rev Orthop Dento Faciale. 1975;9:129-42.

17. Cocconi R, Raffaini M, Amat P. De I'orthodontie à la chirurgie ortho-faciale. Entretien avec Renato Cocconi et Mirco Raffaini. Orthod Fr. 2016;87:247-71.

18. Cozza P, Baccetti T, Franchi L, Toffol LD, McNamara JA. Mandibular changes produced by functional appliances in Class II malocclusion: a systematic review. Am J Orthod Dentofacial Orthop 2006;129:599.e1-12.

19. Creekmore TD. Inhibition or stimulation of vertical growth of the facial complex: its significance to treatment. Angle Orthod 1967;37:285-97.

20. D'Antò V, Bucci R, Franchi L, Rongo R, Michelotti A, Martina R. Class-Il functional orthopaedic treatment: a systematic review of systematic reviews. J Oral Rehabil. 2015;42:624-42.

21. Delaire J. L'évaluation $<<$ morphologique $>$ du poten-tiel de croissance de la mandibule (les signes du $<<$ turfiste $>$ ). Orthod Fr. 1995;66:465-78.

22. DeVincenzo JP. Changes in mandibular length before, during, and after successful orthopedic correction of Class-II malocclusions. Am J Orthod Dentofacial Orthop. 1991;99:241-57.

23. DiCenso A, Bayley L, Haynes B. Accessing pre-ap praised evidence: fine tuning the $5 S$ model into a 6S model. Evidence-based nursing. 2009;12:99-101.

24. Dimberg L, Arnrup K, Bondemark L. The impact of malocclusion on the quality of life among children and adolescents: a systematic review of quantitative stud ies. Eur J Orthod. 2015;37:238-47.

25. El H, Palomo J. Airway volume for different dentofacial skeletal patterns. Am J Orthod Dentofacial Orthop. 2011;139:E511-E521.

26. Fox N. Longer Orthodontic treatment may result in greater external apical root resorption. Evid Based Dent. 2005; 6:21.

27. Forrest JL. Introduction to the basics of Evidence-Based Dentistry: 2. Concepts and skills. J Evid Base Dent Pract 2009:9:108-12.

28. Glendor U. Epidemiology of traumatic dental injuries-a 12 year review of the literature. Dent Traumatol. 2008;24:603-11.

29. Haynes RB. Of studies, syntheses, synopses, summaries, and systems: the "5S" evolution of information services for evidence-based healthcare decisions. Evid Based Med. 2006; 11:162-4.

30. Huynh NT, Desplats E, Almeida FR. Orthodontics treatments for managing obstructive sleep apnea syndrome in children: A systematic review and meta-analysis. Sleep Med Rev. 2016;25:84-94.

31. Isacsson G, Carlson DS, McNamara JA Jr, Isberg AM. Effect of maxillomandibular fixation on condylar growth in juvenile Macaca mulatta: a cephalometric and histologic study. Scand J Dent Res. 1993;101:103-9. 
32. Iwasaki T, Takemoto Y, Inada E, Sato H, Saitoh I, Kakuno E, Yamasaki Y. Three-dimensional cone-beam computed tomography analysis of enlargement of the pharyngeal airway by the Herbst appliance. Am J Orthod Dentofacial Orthop. 2014;146:776-85.

33. Johnson $E$, Roth $T$. An epidemiologic study of sleep-disordered breathing symptoms among adolescents. Sleep. 2006;29:1135-42.

34. Johnston LE Jr. A comparative analysis of Class II treatments. Vig PS, Ribbens KA, (eds):Science and clinical judgment in Orthodontics. Ann Arbor, MI: Center for Human Growth and Development, The University of Michigan, Cranio-facial Growth Series. 1986:103-48.

35. Johnston LE Jr. Functional appliances: a mortgage on mandibular position. Aust Orthod J. 1996;14:154-56.

36. Johnston LE Jr. Growth and the Class II patients: rendering unto Caesar. Seminars in Orthodontics. 1998;4:59-62.

37. Kandasamy S, Goonewardene M. Class II Malocclusion and sleep-disordered breathing. Semin Orthod. 2014;20:316-23.

38. Lager $\mathrm{H}$. The individual growth pattern and stage of maturation as a basis for treatment of distal occlusion with overjet. Trans Eur Orthod Soc. 1967;43:137-45.

39. Lande MJ. Growth behavior of the human bony facial profile as revealed by serial cephalometric roentgenology. Angle Orthod. 1952;22:78-90.

40. Lautrou A. Activateur et force extra-orale à charnière. Rev Orthop Dento Faciale. 1993;27:377-80.

41. Levander $E$, Malmgren $\mathrm{O}$. Evaluation of the risk of root resorption during orthodontic treatment: a study of upper incisors. Eur J Orthod. 1988;10:30-8.

42. Lundström A, Mc William JS. Dentoalveolar compensation for the antero-posterior variations between the upper and lower apical bases. Europ J Orthod. 1984;6:116-22.

43. Marsico E, Gatto E, Burrascano M, Matarese G, Cordasco G. Effectiveness of orthodontic treatment with functional appliances on mandibular growth in the short term. Am J Orthod Dentofacial Orthop. 2011;139:24-36.

44. McNamara JA. Components of Class II malocclusion in children 8-10 years of age. Angle Orthod. 1981;51:177202.

45. McNamara JA Jr, Bryan FA. Long-term mandibular adaptations to protrusive function: an experimental study in Macaca mulatta. Am J Orthod Dentofacial Orthop. 1987;92:98-108.

46. Meikle MC. What do prospective randomized clinical trial tell us about the treatment of Class II malocclusion? Eur J Orthod. 2005;27:105-14.

47. Moyers R, Riolo M, Guire K, Wainwright R, Bookstein F. Differential diagnosis of Class II Malocclusion. Am J Orthod Dentofacial Orthop. 1980;78:477-94.

48. Muto T, Yamazaki A, Takeda S. A cephalometric evaluation of the pharyngeal airway space in patients with mandibular retrognathia and prognathia, and normal subjects. Int $\mathrm{J}$ Oral Maxillofac Surg. 2008;37:228-31.

49. Nguyen QV, Bezemer PD, Habets L, Prahl-Anderesen B. A systematic review of the relationship between overjet size and traumatic dental injuries. Eur J Orthod. 1999;21;503-15.

50. NHS Centre for Reviews and Dissemination. Undertaking systematic reviews of research on effectiveness: CRD's guidance for carrying out or commissioning reviews (2nd edition). York: NHS Centre for Reviews and Dissemination, University of York, 2001.

51. Pancherz $\mathrm{H}$. The effects, limitations, and long-term dentofacial adaptations to treatment with the Herbst appliance. Semin Orthod. 1997;3:232-43. 
52. Perinetti G, PrimozicJ, Franchi L, Contardo L. Treatment Effects of Removable Functional Appliances in Pre-Pubertal and Pubertal Class II Patients: A Systematic Review and Meta-Analysis of Controlled Studies. PLoS One. 2015 Oct 28;10(10):e0141198.

53. Pétrovic AG, Oudet CL, Gasson N. Effet des appareils de propulsion et de rétropulsion mandibulaire sur le nombre des sarcomères en série du muscle ptérygoïdien externe et sur la croissance du cartilage condylien du jeune rat. Orthod Fr. 1973;44:191-212.

54. Petrovic AG, Stutzmann JJ, Gasson N. The final length of the mandible: Is it genetically determined? In: Carlson DS, ed. Cranio-facial Biology. Monograph 10. Cranio-facial Growth Series. Ann Arbor: Center for Human Growth and Development, The University of Michigan, 1981.

55. Petrovic AG, Stutzmann JJ, Oudet CL. Control processes in the postnatal growth of the condylar cartilage of the mandible. In: McNamara JA Jr, ed. Determinants of mandibular form and growth. Monograph 4 (p. 101153). Craniofacial growth series. Center for human growth and development. University of Michigan ed., Ann Arbor, 1975.

56. Petti S. Over two hundred million injuries to anterior teeth attributable to large overjet: a meta-analysis. Dent Traumatol. 2015;31:1-8.

57. Philippe J. 50 ans de récidive. Orthod Fr. 2000;71:87-93.

58. Rizk $s$, Kulbersh vp, al-Qawasmi r. changes in the oropharyngeal airway of Class II patients treated with the mandibular anterior repositioning appliance. Am J Orthod Dentofacial Orthop. 2015;148:618-27.

59. Robin P. Eumorphie: la glossoptose, un grave danger pour nos enfants. Paris: Éditions Semaine Dentaire, 1928.

60. Sackett D. Rules of evidence and clinical recommendations. Can J Cardiol 1993:9:487-9.

61. Sackett DL, Rosenberg WM, Gray JA, Haynes RB, Richardson WS. Evidence based medicine: what it is and what it isn't. BMJ. 1996;312:71-2.

62. Segal GR, Schiffman PH, Tuncay OC. Meta analysis of the treatment-related factors of external apical root resorption. Orthod Craniofac Res. 2004;7:71-8.

63. Solow B. The dentoalveolar compensatory mechanism:background and clinical implications. Br J Orthod. 1980;7:145-61.

64. Stutzmann JJ, Petrovic AG. Role of the lateral pterygoid muscle and meniscotemporomandibular fre-num in spontaneous growth of the mandible and in growth stimulated by the postural hyperpropulsor. Am J Orthod Dentofacial Orthop. 1990;97:381-92.

65. Talmant J, Talmant J-C, Deniaud J, Amat P. Du traitement étiologique des AOS. Rev Orthop Dento Faciale. 2009;43:253-59.

66. Thiruvenkatachari B, Harrison JE, Worthington HV, O'Brien KD. Orthodontic treatment for prominent upper front teeth (Class II malocclusion) in children. Cochrane Database of Systematic Reviews 2013, Issue 11. Art. No.: CD003452. DOI: 10.1002/14651858.CD003452.pub3.

67. Tieu LD, Saltaji H, Normando D, Flores-Mir C. Radiologically determined orthodontically induced external apical root resorption in incisors after non-surgical orthodontic treatment of Class II division 1 malocclusion: a systematic review. Prog Orthod. 2014 Jul 23;15:48.

68. Ulusoy C, Canigur Bavbek N, Tuncer B, Tuncer C, Turkoz C, and Gencturk Z. Evaluation of airway dimensions and changes in hyoid bone position following Class II functional therapy with activator. Acta Odontol Scand. 2014;72:917-25. 
69. Vaid NR, Doshi VM, Vandekar MJ. Class II treatment with functional appliances: A meta-analysis of short-term treatment effects. Semin Orthod. 2014;20:324-338.

70. Verma G, Nagar A, Singh G, Singh A, Tandon P. Cephalometric evaluation of hyoid bone position and pharyngeal spaces following treatment with Twin-block appliance. J Orthod Sci. 2012;1:77-82.

71. Wieslander L. Long term effect of treatment with the headgear-Herbst appliance in the early mixed dentition: Stability or relapse. Am J Orthod Dentofacial Orthop. 1993;104:319-29. 